AN EVALUATION STUDY OF AN

ALTERNATIVE MIDDLE SCHOOL

AT-RISK PROGRAM

\author{
A Dissertation \\ presented to \\ the Faculty of the Graduate School \\ at the University of Missouri-Columbia \\ In Partial Fulfillment \\ of the Requirements for the Degree \\ Doctor of Education \\ by \\ RACHEL BAKER \\ Dr. Cynthia MacGregor, Dissertation Supervisor \\ AUGUST 2008
}


The undersigned, appointed by the dean of the Graduate School, have examined the dissertation entitled

\section{AN EVALUATION OF AN ALTERNATIVE MIDDLE SCHOOL AT-RISK PROGRAM}

presented by Rachel Baker,

a candidate for the degree of doctor of education, and hereby certify that, in their opinion, it is worthy of acceptance.

\begin{tabular}{c}
\hline Dr. Cynthia MacGregor \\
\hline Dr. William Agnew \\
\hline
\end{tabular}

Dr. Jeffrey Cornelius-White

Dr. Kim Finch

Dr. Robert Watson 
C Copyright by Rachel Baker 2008 All Rights Reserved 


\section{DEDICATION}

I would like to thank my wonderful husband, Greg, for all the support he gave me over this endeavor. He was always understanding of all the time I had to spend studying and writing. He never once complained and always celebrated my milestones along the way. I would like to thank my parents for their continued support and encouragement. They always said I could do anything I wanted to and always encouraged me to try new things. 


\section{ACKNOWLEDGEMENTS}

I would like to thank Dr. MacGregor for all of her help and time. She spent countless hours helping me develop my idea and study and answering questions. I could not have made it to the end without her. I would like to thank Dr. Watson for encouraging me. I would not even be in this program if he had not talked to me about it in a prior class. I would also like to thank the other members of my committee, Dr. Agnew, Dr. Cornelius-White, and Dr. Finch for giving their time and suggestions. Additionally, I would like to thank Dr. Moseman for the advice he gave me when he was advising me in my Master's program. Without his encouragement, I probably would not have pursued anything beyond my Master's. 


\section{TABLE OF CONTENTS}

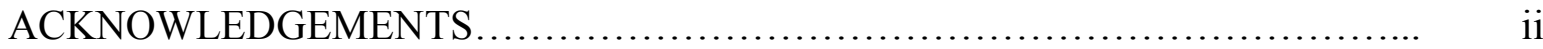

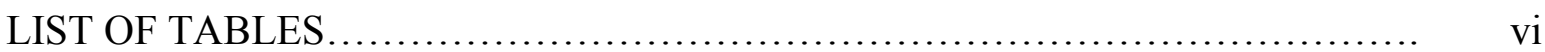

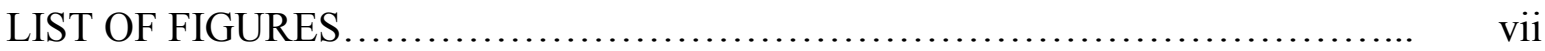

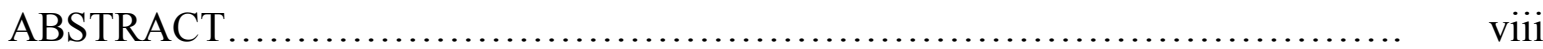

Chapter

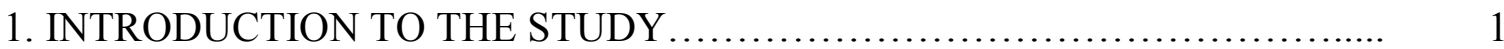

Background........................................................ 1

Conceptual Underpinnings for the Study............................... 5

Statement of the Problem............................................... 7

Purpose of the Study ................................................. 10

Research Questions................................................. 11

Research Hypotheses.............................................. 12

Limitations, Assumptions and Design Controls........................... 12

Definition of Key Terms........................................... 15

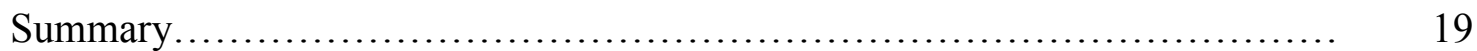

2. REVIEW OF RELATED LITATURE.................................. 21

Introduction................................................... 21

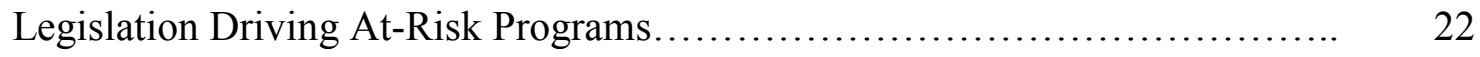

Characteristics of At-Risk Children..................................... 26

Characteristics of Successful Intervention Programs....................... 30

Studies of Effective Middle School and Elementary Alternative Programs........ 41 


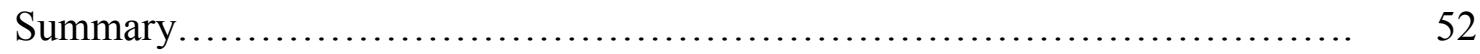

3. RESEARCH DESIGN AND METHODOLOGY ............................. 54

Introduction............................................................ 54

Design of the Study........................................................ 57

Population and Sample.................................................. 58

Data Collection and Instrumentation....................................... 64

Missouri Assessment Program................................................... 66

Interview Protocol........................................................... $\quad 70$

Data Analysis.......................................................... 71

Quantitative Analysis................................................. 71

Qualitative Analysis.................................................... 73

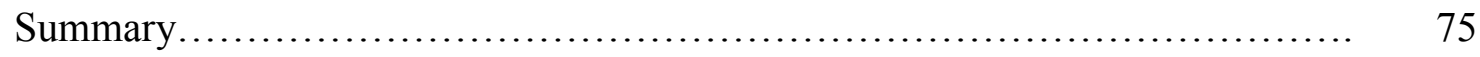

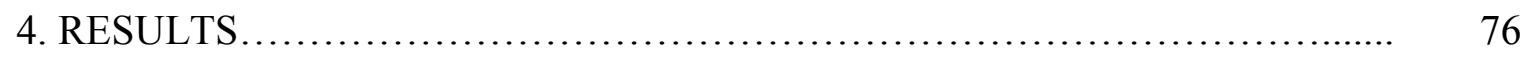

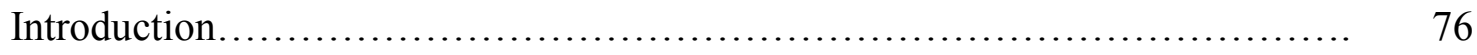

Quantitative Analysis................................................ $\quad 78$

Research Question One............................................... 78

Research Question Two...................................................... 80

Research Question Three............................................. 81

Research Question Four................................................. 85

Qualitative Analysis.................................................... 91

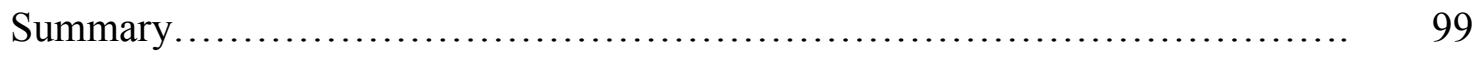

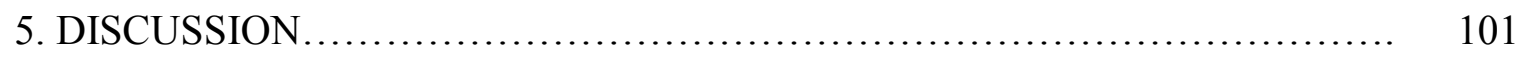


Introduction

Design of Study.................................................. 102

Summary of Findings............................................... 103

Implications for Practice................................................ 108

Limitations....................................................... 114

Recommendations for Further Research............................... 115

REFERENCES............................................................... 119

\section{APPENDIX}

A. GUARDIAN CONSENT FORM........................................ 124

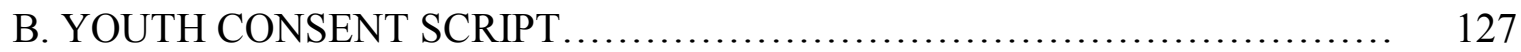

C. FOCUS GROUP INTERVIEW PROTOCOL .............................. 129

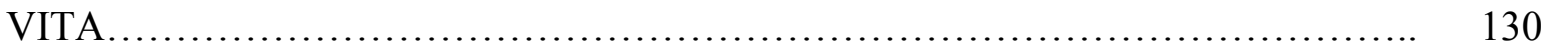




\section{LIST OF TABLES}

Table

Page

1. Percentages of Mathematics and Communication Arts Scores on the MAP 2006. 60

2. Percentages of Mathematics and Communication Arts Scores on the MAP 2007.61

3. Summary of Benchmarks for the No Child Left Behind Act of 2001 for School

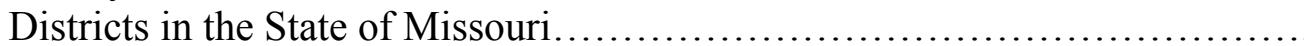

4. Academic Recovery Students Categorical Placements for the Communication Arts Section of the MAP Test................................................

5. Academic Recovery Students Categorical Placements for the Mathematics Section of the MAP Test...............................................

6. Comparison of Gain Scores on the Communication Arts Component of the MAP from 2005-2006 to 2006-2007

7. Comparison of Means for the Communication Arts Component of the MAP...

8. Comparison of Categorical Placements on the Communication Arts Component of the MAP

9. Comparison of Gain Scores on the Mathematics Component of the MAP from 2005-2006 to 2006-2007

10. Comparison of Means for the Mathematics Component of the MAP

11. Comparison of Categorical Placements on the Mathematic Component of the MAP.... 


\section{LIST OF FIGURES}

$\begin{array}{ll}\text { Figure } & \text { Page }\end{array}$

1. Outline of Qualitative Themes and Related Sub-Themes........................92 


\begin{abstract}
The study examined the effectiveness of a middle school alternative program, titled academic recovery, in improving student scores on the state assessment and student outlook on education. A mixed design was utilized to answer the proposed research questions. The quantitative component of this study analyzed the growth of the test scores of the students in this program on the state assessment for one year in communication arts and mathematics. Additionally, the student's growth on the state assessment was compared to the growth of a similar group of students who qualified for the program but were not enrolled in the program. The qualitative component of the study examined student perceptions of their experiences in the academic recovery program.

Students in the academic recovery program were found not to have statistically improved on the state assessment in communication arts and mathematics, and they did not statistically improve more on the state assessment in communication arts and mathematics than a similar group of their peers. However, students in academic recovery classes did have slightly larger gains in their test scores on the state assessment than their peers, and they went from having test scores that were statistically different than their peers to having test scores that were not statistically different than their peers after one year in the program. Through the qualitative analysis it was found students had developed a positive connection with their teacher, had formed friendships at school, and had developed some interests at school. Nevertheless, the students were still struggling academically at school and sometimes felt they were bullied by peers. They were angry at their non academic recovery teachers and were uncertain of their future plans.
\end{abstract}


As a result, several implications for educators surfaced. Educators need to continue to identify at-risk students earlier, eliminate retention programs, facilitate the development of positive relationships, facilitate student involvement, develop transition programs, and develop career counseling programs in middle school. Further research needs to be conducted to determine if academic recovery students are successful in high school, explore teacher and parent perceptions of the program, and to examine the academic recovery program through other lenses and frameworks. 


\section{CHAPTER ONE \\ INTRODUCTION TO THE STUDY}

\section{Background}

Student dropout rates have not decreased in the last twenty years in the United States of America (Leckrone \& Griffith, 2006), and the national graduation rate has steadily declined since 1984 (Wheelock \& Miao, 2005). As a result, school districts have been placed under numerous mandates to fix this problem. In 2001, the federal government passed the No Child Left Behind Act with the goal of increasing student achievement (Primont \& Domazlicky, 2006). At the same time, "the number of students served in alternative schools has increased significantly over the past 10 years" (McLaughlin \& Vactha, 1992; Menendez, 2007, p. 19). As a result, school leaders have been forced to create new, inventive ways to help at-risk students graduate from high school.

The increase in the number of at-risk students is evidenced best by the bottleneck of students in the ninth grade (Wheelock \& Miao, 2005). This is a result of ninth grade students having a difficult time being successful in high school, as student promotion goes from a social promotion program to a credit promotion program. In high school, students are no longer promoted to the next grade socially; they have to earn enough credits to be promoted.

Frequently, in elementary and middle school, students are promoted to the next grade level with their peers, even though they may have failed multiple subjects; this is partially due to the fact retention has proven to be an ineffective tool at improving student achievement (Owings \& Kaplan, 2001). The bottleneck in the ninth grade is occurring 
because many freshman students are not earning enough credits to proceed to their tenth grade year; therefore, they join the group of incoming ninth grade students. Woelfel (2003) stated the reason for the bottleneck is "because more and more states mandate in their school reform legislation that low-achieving students be retained" (Woelfel, p. 45). This is a concern because numerous studies have concluded persistence to graduation is lower for students that repeat ninth grade (Wheelock \& Miao, 2005).

Social promotion and retention programs fail because they often do not provide an intervention strategy to improve student achievement (Russo, 2005). The underlying philosophy of retention programs is the assumption giving students another year to master material will improve student performance (Owings \& Kaplan, 2001). Educators are not questioning why students did not master material the first time. The practice of retention has been ineffective as students often do not perform better the second time around (Russo, 2005). It has been concluded "a single retention increases the likelihood of dropout by a factor of 10" (Ezarik, 2003, p. 35); the older the student is when they are retained the more likely they will drop out of school (Russo, 2005). Social promotion programs do not require students to be accountable for their education. Students learn it does not matter how they do in school; they will proceed to the next grade level regardless of their academic success (Owings \& Kaplan, 2001).

Research has indicated students who do not perform well in school often are discipline problems in the classroom (Suh, Suh, \& Houston, 2007). When students become convinced they are not good learners and will not be successful in school, they misbehave in and out of the classroom to receive attention and feel power (Lapoite \& Legault, 2004). This type of deviant behavior has "been well documented to have a direct 
impact on high school graduation rate" (Suh et al., p. 196). However, students who are considered resilient, students who succeed in school despite obstacles in their way, "believe they are an integral part of society" ( Edward, Mumford, Shillingford, \& SerraRoldan, 2007, p. 147) and "experience a positive school climate, interacting with many caring teachers" (Edward et al., p. 147); suggesting the need for educators to develop connections to students (Cornelius-White, 2007).

As a result of the increasing number of students failing in school, educational leaders have developed numerous alternative programs to help students considered at-risk graduate from high school. "Alternative schools typically provide a somewhat individualized curriculum designed to meet the varied needs of individual students who have, in most cases, not experienced success in traditional public school classrooms" (Menendez, 2007, p. 19). An individualized curriculum is needed because at-risk youth are challenged by different problems than their peers; therefore, alternative strategies need to be used to educate these students (Suh et al., 2007). Several strategies have been found successful reaching at-risk children. Ezarik (2003) suggested restructuring the school day to provide at-risk students with more in-class support since it is difficult getting these students to stay after school for extended learning day programs. Additionally, Ezarik suggested at-risk programs start small with a few children and stressed the importance of continuing to help these children as they proceed through school to guarantee student success.

Woelfel (2003) reiterated this thought when suggesting the need for at-risk students to keep the same teacher for multiple years to allow for the teacher/student relationship to grow, resulting in increased support for at-risk students. Flores and Kaylor 
(2007) found teachers who used a direct instruction teaching style in a middle school mathematics program improved student performance on middle school math objectives defined by the National Council of Teachers of Mathematics. The authors also found students receiving a direct instruction type of program also behaved better than they did in a traditional classroom setting. They were on-task a bigger percentage of the time and were more engaged in their education. Research about alternative programs for educating at-risk youth suggests programs that addressed more than just academics and were personalized to the students were successful at improving student achievement (Woelfel, 2003).

"Students in urban settings are often at a disadvantage educationally compared to their peers in suburban areas" (Kourea, Cartledge, Musti-Rao, 2007, p. 95). With the increasing number of economically disadvantaged students in urban areas, educational leaders in these areas have to provide more services and programs to students at-risk of dropping out of school. The majority of alternative programs are found at the high school level because more programs "require children to be unsuccessful or fail" (Edward et al., 2007, p. 145) before they are identified as at-risk.

School districts often do not identify failing students until they have to repeat their freshman year of high school. This is evidenced by the growing number of students in the ninth grade versus the other grades (Wheelock \& Miao, 2005). "When intervention is delayed until multiple problems are manifested, intensive efforts may be needed, and the impact of the intervention strategy may be reduced" (Suh et al, 2007, p. 196). Therefore, most alternative programs for at-risk students need to be starting in elementary and middle school. Middle school is an important time in a child's education (Flores \& 
Kaylor, 2007), and consequently, "students who are at-risk in middle school need a second chance for success" (Woelfel, 2003, p. 45).

The study outlined in this paper researched a middle school at-risk program, entitled academic recovery, in a school in an urban setting in Missouri. The at-risk program was designed to help struggling middle school students become successful in school and be prepared for high school. Students qualified for academic recovery classes if they were two or more years behind academically, were not in special education, and were not behavior problems in the classroom. The academic recovery program was a result of middle school counselors, administrators, and teacher's identification of the need for a middle school at-risk program. The classes were small classes, consisting of five to twelve students, and the classes were taught by the same teacher across grade levels. In some cases the students had the same teacher for their sixth, seventh, and eighth grade communication arts and mathematics classes.

\section{Conceptual Underpinnings for the Study}

The school district in this study had three overreaching board goals that transcended all decisions made in the district. They were: (a) improve student achievement, (b) improve graduation rate, and (c) ensure effective and efficient use of resources (School District Handbook, 2007). The academic recovery classes at the middle school level came about as a way to improve board goals one and two: improving student achievement and improving the graduation rate. The focus of the research project addressed the district's third board goal by examining the amount of money invested in academic recovery classes. The research was conducted using Patton's (1997) utilizationfocused evaluation approach. The goal of the research was to determine if the program 
was meeting the goals the intended users, the counselors, intended when they developed the classes.

Patton's (1997) approach to evaluation specified the evaluator should work "with intended users to extract and specify their implicit theory of action" (Patton, p. 219). After conversations with counselors involved with academic recovery classes, it was determined school leaders held a belief that students become at-risk because of “environmental deficits" (Sagor \& Cox, 2004, p. 279). The theory that a student becomes at-risk because of deficits in their environment is based on the thought these students have missed "certain experiences" (Sagor \& Cox, p. 279), and therefore, accelerated programs should be developed that intend to re-teach missing skills and concepts for mastery. The focus of the research was to help improve the program and give the district information it could use to improve the decisions made concerning the academic recovery program classes (Patton, 1997).

Patton's (1997) utilization-focused evaluation model specifies seven steps for the researcher/evaluator to follow, after identifying the theory of action, to facilitate an effective evaluation. First, an effective amount of resources should be dedicated to the evaluation. This includes time on all ends, researcher and stakeholders, and money. Second, the evaluators should work with the intended users, stakeholders, of the program to identify research questions and the evaluation design. Intended users would be administrators, teachers, counselors, and students. Third, these aforementioned stakeholders should be involved in every step of the evaluation. Fourth, the researcher should study how the stakeholders react to being involved in the evaluation at every stage. Fifth, the findings of the evaluation should provide the intended users with new 
knowledge and understandings about the academic recovery program. Sixth, the stakeholders should be the one to interpret results, not the evaluator. Seventh, the academic recovery program should improve as a result of decisions made by intended users based on the findings of the evaluation (Patton, 1997, p. 234).

Utilization-focused evaluation theory is grounded in the idea that "evaluation can make an ongoing contribution to program involvement as program staff and other primary stakeholders learn to use evaluation concepts to shape and test program ideas" (Patton, 1997, p. 229). This research study aimed to determine if academic recovery classes were improving student achievement. Thus, it aimed to help intended users answer the following questions: Did the implemented program help to improve student achievement in communication arts and mathematics? Did the implemented program change student perceptions about school?

The program used several characteristics of effective alternative programs for atrisk youth. It provided "extended learning opportunities for students at risk of retention" (Ezarik, 2003, p. 37) and it restructured "the school day to provide more in-class support for students at risk of retention" (Ezarik, p. 37). The program also consisted of small homogenous classes (Schweiker-Marra \& Pula, 2005) with the same teacher for multiple years to build connections (Edward et al., 2007). The theory of using these effective strategies, combined with Patton's (1997) theory of utilization focused evaluation, served as the theoretical underpinnings for this study.

\section{Statement of the Problem}

The No Child Left Behind Act of 2001 required all public school systems in the United States to improve student achievement. More specifically, the act required all 
students test proficient in mathematics and communication arts by the year 2014 on their state assessment. School districts that did not meet these demands faced possible sanctions including school closure (Primont \& Domazlicky, 2006). States were given freedom in the development of achievement tests and the definition of proficiency levels. State educational leaders were also in charge of the development of the timeline used to measure school progress. In Missouri, the Missouri Assessment Program (MAP) was the standardized test used to determine if schools were meeting compliance of the No Child Left Behind Act. In addition to communication arts and mathematics student test scores on the MAP, school districts were measured on their dropout and graduation rates annually.

As a result, several school districts developed different alternative programs designed to help at-risk students proceed through school and ultimately graduate from high school. The school district in this study developed an academic recovery program designed to help middle school at-risk students (students two or more grade levels behind) perform at grade level in communication arts, reading, and mathematics and develop the skills necessary to be successful in high school. The theory behind the academic recovery classes were small class sizes with the same teacher for several years who would help students be academically successful; hence, students would develop more self esteem and study skills to continue to be academically successful.

While there has been significant research as to what characteristics are common in successful at-risk programs (Edward et al., 2007; Ezarik, 2003; McLaughlin \& Vachta, 1992; Russo, 2005; Suh et al., 2007; Wheelock \& Miao, 2005), very few studies have been conducted to determine what characteristics are unique for successful middle school 
at-risk programs (Flores \& Kaylor, 2007; Woelfel, 2003). Schwieker-Marra and Pula (2005) researched the effects of a homogeneous middle school program for at-risk students. Students were identified to be at-risk if they tested in the lowest quartile of the state test. The students in the study all had been identified as having learning problems or behavior problems in the classroom. They found the homogenous program "did produce a significant decline of at-risk students in the lowest quartile" (Schwieker-Marra, p. 40).

There have been several studies about communication arts intervention programs that have been found to be successful (Denton, Fletcher, Anthony, \& Francis, 2006; Reutzel, Fawson, \& Smith, 2006) and mathematics intervention programs that have been found to be successful (Flores \& Kaylor, 2007), but no research has been conducted that examined a program that worked to improve both mathematics and communication arts. Additionally, there has been a lack of research about alternative programs from the student's perspective. Few programs deal with multiple aspects of student education and even less research exists to examine the impact of such programs.

This study aimed to determine how successful a middle school at-risk program was at improving student performance in communication arts and mathematics as measured by the state achievement test, the Missouri Assessment Program (MAP). The number of students dropping out of high school in the district was not decreasing. If this trend continued, the school district would find it difficult to meet Adequate Yearly Progress (AYP) as defined by the Missouri Department of Elementary and Secondary Education (DESE) and have to face disciplinary sanctions. Decreasing the number of students at-risk of dropping out of school was essential to the improvement of dropout and graduation rates for the district. The academic recovery classes the district offered is 
one intervention the district used to identify students earlier and help them develop the skills necessary to be successful (Suh et al., 2007). The academic recovery program is the emphasis of the research in this study. The problem studied in this research was the performance of at-risk middle school students in academic recovery classes. Therefore, this research aimed to determine if these classes were helping at-risk middle school students improve their academic achievement and perception about school.

\section{Purpose of the Study}

This study was proposed as a possible tool for the school district to use when evaluating the middle school academic recovery program (Patton, 1997). The district was investing a significant amount of money into the program, and many times when buildings in the district had to reduce the number of staff, academic recovery teachers were the first personnel moved. Academic recovery classes had been offered if teachers were available to teach those classes after the assignment of teachers to required courses. The decision was based on the number of fulltime teachers assigned to the school from the central office of the school district. This number was decided by the projected student enrollment of the school. This resulted in an inconsistency of the program and the elimination of the program at certain school sites.

The purpose of this study was to determine how effective an academic recovery program at the middle school level was in improving student academic achievement in communication arts and mathematics, using scores on state assessments as the measure of success. The study compared student test scores in communication arts and mathematics before and after the implementation of the program for students in the academic recovery program classes and students that qualified for the classes but not enrolled in them. 
Additionally, the purpose of this study was to determine student perceptions about their experiences associated with the academic recovery program, and to determine if the program resulted in a positive change of thinking about school for the students (Owings \& Kaplan, 2001). This was defined by an improved outlook of school and life that was evidenced in a focus group interview, in an interview, and in questionnaires.

\section{Research Questions}

Within the context of the study, the following research questions were addressed:

1. What was the effect of academic recovery classes on the state assessment, as measured by the Missouri Assessment Program (MAP) test in communication arts, on middle school students (grades 6, 7, and 8) enrolled in academic recovery classes?

2. What was the effect of academic recovery classes on the state assessment, as measured by the MAP test in mathematics, on middle school students (grades 6, 7, and 8) enrolled in academic recovery classes?

3. What was the comparison of middle school student test scores, as measured by the communication arts of the MAP test, of middle school students (grades 6,7, and 8) in academic recovery classes and students qualified for academic recovery classes but not enrolled in academic recovery classes?

4. What was the comparison of middle school student test scores, as measured by the mathematics component of the MAP test, of middle school students (grades 6, 7, and 8) in academic recovery classes and students qualified for academic recovery classes but not enrolled in academic recovery classes? 
5. What were the perceptions of middle school student's (grades 6, 7, and 8) experiences in academic recovery classes?

\section{Research Hypotheses}

The following research hypotheses were examined:

Hypothesis 1: Student test scores in communication arts as measured on the MAP improved (alpha level .05) for students in academic recovery classes.

Hypothesis 2: Student test scores in mathematics as measured on the MAP improved (alpha level .05) for students in academic recovery classes.

Hypothesis 3: Students in academic recovery classes had greater increases in communication arts test scores (alpha level .05) as measured by the MAP than students who qualified for academic recovery classes but were not enrolled in the classes.

Hypothesis 4: Students in academic recovery classes had greater increases in mathematics test scores (alpha level .05) as measured by the MAP than students who qualified for academic recovery classes but were not enrolled in the classes.

\section{Limitations, Assumptions, and Design Controls}

There were several limitations for this study, along with assumptions on which the research was based. To account for the limitations and assumptions, the study had some design controls that addressed the limitations. They are addressed in the following sections.

\section{Limitations and Assumptions}

The researcher was limited by time; therefore, the study only addressed two school years. A longitudinal study would provide more detailed information but was not 
feasible. Time also limited the number of focus group interviews, interviews the researcher conducted. The researcher was also limited to the resources provided for the research. This research was not funded, and all research was done by the researcher. There was only one researcher conducting the study, with the exceptions of school counselors locating the data without identifying information (Merriam, 1998; Fink, 2006) and an independent researcher reviewing the qualitative data (Merriam). Additionally, the researcher did not determine the reliability or validity of the questions asked in the focus group interview, an interview, and questionnaires (Appendix C).

This study was limited to one framework; specifically Patton's (1997) utilizationfocused evaluation was used as the theoretical underpinnings for this study. This guided how the study was approached, what questions were asked, and how findings were analyzed. Other lenses may have led to different research questions and findings about the academic recovery program classes. Personal bias may have played a role in the focus of the study and the interpretation of the results, although every attempt was made to control this bias by having an independent researcher review findings.

The focus of this study was on a middle school alternative program that was only four years old in an urban school in Missouri. This program was inconsistent at certain sites as the offering of the classes was determined if the school had enough teachers available to teach the classes. The researcher noted if student enrollment went down, the academic recovery teacher was usually the first teacher transferred to another site. This research focused on three middle school sites in the district that offered academic recovery classes. These classes were available to sixth, seventh, and eighth grade students. This limited the amount of information that was available about the program. 
Additionally, the MAP indicators were changed in 2006 from five stages to four stages which limited the amount of consistent quantitative data the researcher could gather.

The study was developed around several assumptions. It was first assumed the researcher was provided with unbiased information from the site counselors. They gathered the requested data and provided it to the researcher without any identifying information. It was also assumed students in the focus group interview and the personal interview provided the researcher with truthful answers. It was also assumed the students who filled out the questionnaires provided the researcher with truthful answers. Students were identified to be in the interviews if they were enrolled in an academic recovery class, consented to the interview, and their parents had consented to the interviews (Appendix A; Appendix B). There were four students in the focus group interview, one individual student interview, and two questionnaires completed by academic recovery students. Finally, it was assumed the researcher's role in the district did not interfere with the interpretation of the results. To control for this, an independent researcher reviewed the results.

\section{Design Controls}

To address the limitation of time this research project consisted of a case study about three academic recovery programs in a single school district. Three middle schools (grades 6-8) were identified for the study.

The study focused on gathering information that would be useful to the school district to address the limitation of only using Patton's (1997) utilization-focused evaluation lens to develop the study and analyze findings. The study was proposed as a 
possible tool for the school district to use when evaluating the middle school academic recovery program.

The limitation of a rather new program being studied was addressed when the researcher used a formative evaluation process. Formative evaluation processes focus "on ways of improving and enhancing programs rather than rendering definitive judgment about effectiveness" (Patton, 1997, p. 67). The researcher did not "judge the overall effectiveness of" (Patton, p. 67) the program, but rather sought to determine if the classes were effective at improving student scores on standardized tests and to determine what student's experiences were in the classes. Since this was a new program, the purpose of the research was to provide useful data that would help the school district make improvements and changes in the program.

\section{Definition of Key Terms}

\section{Academic Recovery Program}

Students qualified for academic recovery classes if they were two or more grade levels behind academically, were not in special education, and were not behavior problems in the classroom. The academic recovery program consisted of small homogenous class for students that were two or more grade levels behind in middle school. Class sizes ranged from five to ten students. Students had the same teacher for their mathematics academic recovery class and their communication arts academic recovery class. The purpose of the program is for students to perform at grade level in their studies before they enter high school. 


\section{At-risk Student}

The at-risk student exhibits lows performance on basic skills tests and tests below grade level on achievement tests, has low grades in school, often does not complete assignments, has parents who do not monitor school performance and do not encourage the student to be successful in school, and does not see the point of being successful in school (McLaughlin \& Vachta, 1992). At-risk students in the academic recovery program are defined as students who are two or more grade levels behind.

\section{Missouri Department of Elementary and Secondary Education (DESE)}

The Missouri Department of Elementary and Secondary Education (DESE) is the department of education for the state of Missouri. This entity developed the standardized state assessments for the school districts in Missouri. It defined the standards school districts must attain in order to stay accredited every year.

\section{Missouri Assessment Program (MAP)}

The Missouri Assessment Program (MAP) was the standardized test given by the Missouri Department of Elementary and Secondary Education. Test subjects included communication arts, mathematics, social science, science. The communication arts section and the mathematics sections were given to all students in grades three through eight (Missouri Department of Elementary and Secondary Education, 2005b). High school students took the communications arts section in grade eleven and the mathematics section in grade ten. The social science and science sections were grade span tests. The social science sections were given to all students in grades four, eight and eleven. The science section was given to all students in grades five, eight, and ten (Missouri Department of Elementary and Secondary Education, 2007b). The MAP was 
designed to measure student achievement as defined by the Show-Me Standards, standards adopted by the state board of educations as to what all students should know and be able to do by the time they graduate high school (Missouri Department of Elementary and Secondary Education, 2005b).

Adequate Yearly Progress (AYP)

Adequate Yearly Progress (AYP) was the tool used by DESE to measure the progress the school district was making at improving state assessment scores and yearly targets in graduation rates and attendance rates set by the state. AYP took into account all subgroup populations in the district. A school district could make yearly targets using the average of all of its students, but if a subgroup did not meet a target the school did not meet AYP. The subgroups measured on AYP were as follows: (a) economically disadvantaged students (student receiving free or reduced lunch), (b) gender groups, (c) major racial and ethnic groups, and (d) special education students. A school was determined to have a subgroup if the school had 30 or more students in categories a, b, or c. A school was determined to have a subgroup population of special education students if there were 50 or more students receiving special education services (Missouri Department of Elementary and Secondary Education, 2007).

\section{No Child Left Behind Act of 2001}

The No Child Left Behind Act was passed by the United States federal legislature in 2001. It had several stipulations, most importantly that every student must test proficient and advanced in communication arts and mathematics on their state achievement test. State departments of education were given until 2014 to meet this goal. Additionally, the law stipulates sanctions will be made against school districts not 
making progress towards the goals. Sanctions could be providing teacher assistance, allowing students the right to transfer to succeeding school, or school closure (United Stated Department of Education, 2007)

\section{Grade Level Expectations}

Grade Level Expectations (GLE's) were the expectations set fourth by DESE that each student must know in a subject by the end of the year. Every curriculum area had grade level expectations defined by DESE for every grade level. The grade level expectations were tied to the Show-Me Standards and were assessed on the MAP test.

\section{Communication Arts Achievement}

Communication Arts Achievement was defined by the number of students who tested proficient and advanced on the MAP communication arts section. Every school district in the nation was required to have all students in grade three through eight test proficient or advanced by the year 2014 according to the No Child Left Behind Act of 2001 (United States Department of Education, n.d.).

\section{Mathematics Achievement}

Mathematics Achievement was defined by the number of students who tested proficient and advanced on the MAP mathematics section. Every school district in the nation was required to have all students in grades three through eight test proficient or advanced by the year 2014, according to the No Child Left Behind Act of 2001(United States Department of Education, n.d.). 


\section{Middle School}

For this study middle schools were defined to be schools with grades six, seven, and eight in one building. All three of the middle schools in the study offered academic recovery classes to students in grades six, seven, and eight.

Level of Confidence

An alpha level of less than 0.5 was used for this study. If the alpha level was less than 0.5 for statistical tests run, it was determined the difference was statistically significant.

Chi-Square Test

A chi-square test of independence tests "whether two categorical variables forming a contingency table are associated" (Field, 2005, p. 725). Independent T-Test

An independent $t$-test is a "test using the $t$-statistic that establishes whether two means collected from independent samples differ significantly" (Field, 2005, p. 734).

\section{Summary}

The background for the study, the conceptual underpinnings for the study, the research problem, and the purpose for the study were addressed and discussed in chapter one. Additionally, limitations and assumptions for the study were delineated and key terms were defined. The number of at-risk students is increasing (McLaughlin \& Vachta, 1992) and dropout rates are increasing (Wheelock \& Miao, 2005). The No Child Left Behind Act of 2001 required school districts to improve student achievement and make adequate yearly progress towards meeting the standard of every child proficient in reading and mathematics by the year 2014 (Primont \& Domazlicky, 2006). As a result, 
one school district in southwest Missouri developed a program to help at-risk middle school students.

This program was developed as a result of school leaders identifying the need of a program in middle school to help underachieving students. The program was a relatively new program and was evaluated using Patton's (1997) theory of utilization focused evaluation. This programs goal was to improve student achievement at the middle school level, in hopes of lowering the number of student dropouts in high school. This study examined the effectiveness of this program by using the MAP Test as a measure of success and using focus group interviews (Kreuger \& Casey, 2000) to determine the experiences and perceptions of students in the program.

A literature review of related research and findings about at-risk students and characteristics of effective at-risk programs is presented in chapter two. Chapter three details the design of the mixed study. Research questions, hypotheses, and the research design are delineated. The results of the quantitative piece and qualitative piece are presented in detail in chapter four. Chapter five includes a summary of the study and presents the findings of the study. Implications for practice in education and recommendations for further studies are also addressed in chapter five. Appendices of the consent form used for the participant's guardians (Appendix A), the participants youth consent script, (Appendix B) and the interview protocol (Appendix C) are available for review following the reference list. 


\section{CHAPTER TWO \\ REVIEW OF RELATED LITERATURE \\ Introduction}

Alternative programs designed to help at-risk students graduate from high school are being implemented at school districts across the United States (Woelfel, 2003). "The number of alternative schools has increased significantly over the past 10 years" (Menendez, 2007, p. 19). The number of programs addressing the needs of at-risk students has multiplied and many schools are including the achievement of at-risk youth in their school mission and goals (Owings \& Kaplan, 2001). The curriculum of these programs varies, but alternative programs provide a curriculum that is focused on each child individually (Menendez, 2007). "Just as individual students can be at risk for school failure, so can schools be at risk when they do not provide an environment for learning" (Vaughn, Bos, \& Schumm, 2007, p. 301); this means schools have to provide an environment for learning for all students.

The focus of this research project is an alternative program at a middle school aimed at helping at-risk students get back on grade level before they proceed to high school. To provide a context for the study, the focus of the literature review centers on atrisk youth and at-risk programs. First, legislation driving at-risk programs is reviewed. Second, characteristics of at-risk youth are outlined. Third, characteristics of effective atrisk programs are presented. Fourth, studies of successful alternative programs are detailed. Fifth, long term consequences and implications of not helping at-risk students are discussed. 


\section{Legislation Driving At-Risk Programs}

Education in the United States is continually evolving. Every child in America can receive a free education. As the country has grown, educators and lawmakers have continually made improvements to the quality of education. The country's economic viability depends on the education of the future generations (Barr \& Parrett, 1995). To ensure the country's economic viability, lawmakers have made mandates public school systems have to maintain. Throughout the years, federal laws have made education more equitable for all social classes and have increased expectations. Today the focus is on improving student achievement for at-risk students in hopes of improving graduation rates and producing more qualified workers in the workforce. Fifty years of legislation lead to this reform in schools.

The American education system was drastically changed in the 1950's and 1960's as America was beginning to compete globally and the civil rights movement gained momentum. Legislation to equate the quality of education for all students was first passed in 1954. Two major events happened that changed public education forever. First, the "School Milk Program Act extended the National School Lunch Act of 1946 to address basic needs of children in poverty" (Vaughn, Bos, \& Schumm, 2007, p. 295). Second, Brown v. Board of Education of Topeka, Kansas, declared it was unconstitutional for public schools to be segregated, and public schools were forced to integrate. In 1964, federal funding for at-risk students was approved with the passage of the Economics Opportunities Act that resulted in the formation of the Head Start program. In 1965, Title I programs for low income students began with the passage of the Elementary and Secondary Education Act (Vaughn et. al.). Title I programs were given funding from the 
federal government to educate disadvantaged children (Center on Education Policy, 2004). Equality in education for minority students and poor students was mandated by the federal government for the first time.

The Individuals with Disabilities Act passed in 1975 changed how educators approached the education of children with all disabilities, physical disabilities, and learning disabilities. These students, perhaps, were some of the first students who were characterized as at-risk of not graduating high school. This disabilities act has been expanded and reauthorized numerous times throughout the 1980's and the 1990's to include more groups and redefine special education (Anthony, 1992). Educators are now being required to provide equitable education for all subgroups of the population.

"The term at risk came into being on publication of the report $A$ Nation at Risk by the National Commission in Excellence in Education" (Vaughn et al., 2007, p. 295). This report in 1983 was a catalyst for change in the public education system in the United States. The number of failing students was exposed to the American public. Students were graduating from high school without the requisite skills needed for the workforce, and, if the trend continued, the United States would find it hard to compete globally. The United States was beginning to struggle with competing "in the international marketplace" (Barr \& Parrett, 1995, p. 2). Educators responded to this by focusing on retention, as they did not want students advancing without mastering required skills (Bowman, 2005). As a result of this report, American education shifted its focus from helping improve student achievement for minority and low income students to helping all students that were disadvantaged (Barr \& Parrett, 1995). The education system was being held under the scrutiny of the public eye for the first time in history. 
The federal government of the United States made the education of at-risk students a bigger focus when it funded the Comprehensive School Reform program (Edward, Mumford, Shillingford, \& Serra-Roldan, 2007). This reform came about in 1998 "when Congress appropriated approximately $\$ 145$ million in competitive grants to state education agencies to improve the educational outcomes of students considered at risk of school failure" (Edward, et al., p. 145). The expectations of the public school system had increased as schools were being held to higher standards.

The Elementary and Secondary Education Act was reauthorized in 2001 as the No Child Left Behind Act. "The law emphasizes increased accountability, focus on researchbased practices, parental options, and local flexibility" (Vaughn et al., 2007, p. 295). This law made schools more accountable for the successful education of all children and placed emphasis on interventions earlier in a child's education; often at-risk students were "identified far too late in their school careers - at a point when interventions are not only less successful but also come at increasing cost” (Sprague \& Walker, 2005, p. 131). School districts were required to make annual yearly progress for all subgroups; if they did not, they were classified as a failing school (Missouri Department of Elementary and Secondary Education, 2004). Failing schools were required to provide additional tutoring and pay for students to transfer to non-failing schools (Primont \& Domazlicky, 2006). As a result, many school districts reexamined their retention policies and made them stricter in hopes of making students become more accountable for their education. At the same time, school officials started looking for ways to help at-risk students become successful in the classroom (Vaughn et al.). Educational systems were now being held accountable for every child's education. 
At the present time, several law suites, including one in Missouri, have developed about the inequitable funding provided to school districts. Wealthy communities with high tax bases are able to spend more dollars per child to educate them. Poor communities, that generally have a higher number of at-risk students to serve, are not able to spend as much money per child to educate them. The education of an at-risk child costs more than the education of an average child because the at-risk child requires more services (Barr \& Parrett, 1995). Funding for educating at-risk children has not kept up with the legislation.

Summary. Educational reform is not new to the American public school system. Major reforms started in the 1950's and the 1960's as the public schools were required to integrate, and legislation was passed that required schools to provide an equitable education to minority students and poor students (Vaughn et al., 2007). In the 1970's, with the passage of the Individuals with Disabilities Act, schools were additionally required to provide an equitable education to students with disabilities (Anthony \& Jacobson, 1992). In the 1980's, the number of failing students in the country was exposed to the public with the publication of $A$ Nation at Risk (Barr \& Parrett, 1995). In the 1990's, school districts were beginning to be held to higher standards and the education of at-risk students started to become the focus (Edward et al., 2007; Leckrone \& Griffith, 2006).

Shortly afterwards, the No Child Left Behind Act of 2001 was passed. It held schools accountable to higher standards and placed sanctions on schools that did not meet these standards. Schools were now held accountable for the education of every child, regardless of their status (Sprague \& Walker, 1995; Vaughn et al., 2007). At the present 
time, several law suites are being brought against state departments to resolve the inequities that exist in school funding (Barr \& Parrett, 1995). The American education system has evolved into a system that strives to provide an equitable education for all children everywhere, with increasing focus on students at-risk of not completing high school.

\section{Characteristics of At-Risk Children}

At-risk students are identified as students who are behind grade level and not on track to graduate high school in the standard four years (Woelfel, 2003). Consequently, they tend to test low on basic skills tests and achievement tests, have failing grades at school, and are older than their peers (McLaughlin \& Vachta, 1992). As a result, many of these students view school negatively and do not see hope for their future (Edward et al., 2007). This apathetic feeling, in combination with constantly failing, facilitates an at-risk youth's decision to drop out of school (Suh et al., 2007). These students are creating a huge strain on already stressed school systems. The following sections outline key characteristics of at-risk children. Knowing these characteristics could help educators identify at-risk students earlier. As Barr and Parrett (1995) stated "using only a few identified factors, schools can predict with better than 80 percent accuracy students in the third grade who will later drop out of school" (p. 9). These factors are divided into school factors and family factors.

School factors. Failing grades and test scores are some of the first things school leaders look at when determining if a child is at-risk of not graduating from high school (Suh, Suh, \& Houston, 2007). Many times at-risk students are behind in their academic studies and exhibit low academic achievement. McLaughlin and Vachta (1992) identified 
several characteristics of an at-risk student, a student who is more likely to drop out of school than his or her peers. Of the six characteristics identified, three of them addressed an at-risk student's failure in the classroom and their lack of basic skills. "Students who need additional support in learning these basic skills may be at risk for school failure" (Vaughn et al., 2007, p. 296). Therefore, McLaughlin and Vachta concluded successful alternative programs should focus on basic skills children lack, and they should track and monitor student success.

In a 2005 study of at-risk middle school students, it was found most of the students had a history of learning problems in elementary school that had impeded their success (Schweiker-Marra \& Pula, 2005). They often have a difficult time learning the basics such as reading, writing, and basic arithmetic (Vaughn et al, 2007). These students also tended to display aggressive tendencies and inappropriate behavior. Teachers experienced behavior problems with them, and they were often discipline problems as a result (McLaughlin \& Vachta, 1992). This misbehavior often spread to the whole class and became a disruption to the learning process (Lapointe \& Legault, 2004). When a child has a learning problem, he/she gets a negative attitude towards school and becomes a behavior problem in the classroom because he/she feels like a failure. It becomes harder for a teacher to reach him/her.

At-risk students often do not complete work assigned at school which causes them to receive low grades resulting in failure. When students are given the opportunity to fail, many of them fall through the cracks (McLaughlin \& Vachta, 1992). "Many young people in our nation are led to believe, in some cases early on, that success in school is beyond their reach" (Vaughn et al., 2007, p. 294). Therefore, Woelfel (2003) suggested 
students not be given the opportunity to fail, citing the success of a middle school at-risk program in Michigan. Students in this program were not allowed to turn in incomplete work; teachers assigned incomplete grades instead of failing grades, not accepting failure. As a result, the school district decreased the number of retentions and improved student achievement.

There are many characteristics at-risk students exhibit at school. They often have failing grades, low test scores, and lack basic skills (Edmonds, 1979; McLaughlin \& Vachta, 1992, Vaughn et al., 2007). Additionally, at-risk students often suffer from learning problems, and as a result, are discipline problems in school (McLaughlin \& Vachta, Schweiker-Marra \& Pula, 2005, Vaughn et al.). When given the opportunity to fail, these students choose failure (McLaughlin \& Vachta). Therefore, schools cannot give students this opportunity; they have to develop programs that will not allow them to fail (Vaughn et al.; Woelfel, 2003). Students who are at-risk require an education that focuses on more than academics.

Family factors. At-risk students have little support outside of school. Many times their parents are absent, or they do not model a positive outlook about school. These parents do not monitor their child's progress in school and give them little encouragement to do well at school. Most at-risk youth live in a single family home (Barr \& Parrett, 1995), where the parent works long hours and cannot supervise their child at home. As a result, these children have little support, see no point in schoolwork, and do not comprehend the benefits of schooling for future work. Typically, at-risk students are not involved in extracurricular activities and are not interested in school (McLaughlin \& Vachta, 1992). However, Vaughn et al. (2007) did caution for educators to not assume 
these parents "do not care about their children's progress in school and are not capable of making substantive contributions to their children's education" (p. 325). These parents need to be invited into the school and taught how to work with their child at home, support their child, and be involved at school.

At-risk students often come from low socioeconomic homes, minority families, and are students that frequently move and live in rental homes (Barr \& Parrett, 1995; Schweiker-Marra \& Pula, 2005; Vaughn et al., 2007). They move from school to school which makes it hard for them to develop a connection to school, potentially leading to low attendance (McLaughlin \& Vachta, 1992). Attendance rates for at-risk students are lower than attendance rates for average students (McLaughlin \& Vachta, 1992; Vaughn et al., 2007). Suh et al. (2007) and Franklin, Streeter, Kim, and Tripodi (2007) confirmed in their studies the number of days absent from school and the total numbers of schools attended are predictors of dropouts. A study about student mobility found for "those who had moved once, the graduation rate was 68 percent; for those who had moved three times, only 30 percent” (Barr \& Parrett, p. 13). Low socioeconomic status and poor attendance at school increases the chances of a child performing poorly at school.

Suh, Suh, and Houston (2007) proved poverty was a common characteristic of atrisk students. The authors conducted a study to "identify and compare different factors that contribute to school dropout rates among three groups of at-risk students" (Suh et al., p. 196). In the study, at-risk referred "to aspects of a student's background and environment that may lead to a higher risk of her or his educational failure" (Suh et al., p. 196). The three groups were low socioeconomic class, poor achievement at school, and school suspensions. All three of these factors were proven to be predictors of student 
dropouts, suggesting the need for alternative programs to be implemented early in poverty stricken areas to decrease the likelihood of a student dropping out of school.

Summary. Schools cannot control family factors that contribute to the chances a child will be academically unsuccessful, but the awareness of them can help educators understand this problem and implement appropriate programs. At-risk students typically come from single family homes and receive little support at home (Barr \& Parrett, 1995). As a result, they are not involved in extracurricular activities as school; they do not feel a connection to school (McLaughlin \& Vachta, 1992). This is usually precipitated by the fact students at-risk come from poor homes, frequently move, and have low attendance at school (Barr \& Parrett; McLaughlin \& Vachta, Schweiker-Marra \& Pula; 2005; Suh et al., 2007; Vaughn et al., 2007). Knowing the characteristics of at-risk students helps educators identify these students earlier and develop programs that can effectively address their needs.

\section{Characteristics of Successful Intervention Programs}

According to McLaughlin and Vachta (1992), several in class and pull out programs have been found to be successful at helping at-risk students achieve at school. The traditional methods of treating failing students, i.e., retention and social promotion, have been proven to be unsuccessful at improving student achievement. It has been found that "a single retention increases the likelihood of dropout by a factor of 10" (Ezarik, 2003, p. 35). Additionally, a previous survey found "a vast majority of parents, teachers, employers, and professors (plus a majority of students) surveyed said that promoting a struggling child is worse than retaining that child" (Ezarik, p. 36). As a result, school leaders have been forced to develop alternative intervention programs to help struggling 
students succeed. The following paragraphs outline the characteristics of successful alternative education programs.

The development of positive relationships and connections. Successful alternative programs focus on the development of positive relationships and connections to school (Cornelius-White, 2007). Edward et al. (2007) contended the best way to approach the education of at-risk students was to use a preventative approach intended to increase a child's "resiliency by building developmental assets" (Edward et al., p. 145). Resiliency was defined as the ability of an at-risk student to respond and cope with the adversity in their life positively. According to the study, resilient children felt they had a significant role to fulfill in society, felt connected to society, and had an understanding of how actions today will impact their choices after high school (Edward et al., Suh et al., 2007). They were supported by role models and worked with others well.

Suh et al. (2007) recommended educators begin career counseling early in a child's education in middle school. Counseling students early was thought to help students realize their own self worth, believe in themselves, and learn appropriate coping strategies (Johnson, Poliner, \& Bonaiuto, 2005; Suh et al.). Suh et al. declared the necessity for educators to create school climates that allow opportunities to facilitate the development of these skills for all students because "prevention of high-risk behaviors is at the core of building developmental assets" (Barr \& Parrett, 1995; Edward, et al., 2007, p. 149).

A key factor in developing these assets is the building of relationships. Edward et al. (2007) called for teachers to use a teaching style that was nurturing to initiate positive relationships with students. The reasoning was positive teacher/student relationships help 
students feel connected to school resulting in success at school. Continual modeling and building of positive relationships help at-risk students build self-esteem and learn how to make good decisions. "Students are less likely to engage in poor decision making when they believe significant adults in their lives are united and have their best interests at heart" (Edward, et al., p. 151).

Suh et al. (2007) concurred when they found in their study positive teacher relationships were strong predictors of decreasing drop out rates and students who had optimistic futures were not as likely as their peers to drop out of school. They encouraged all educators to purposefully seek out and develop positive relationships with students. As a result, successful alternative programs should facilitate the development of good relationships with others, the development of positive coping skills, and the development of a strong positive sense of oneself.

Owings and Kaplan (2001) suggested schools follow a block schedule to allow students time to develop positive relationships with their teachers and give them more time to master material. Block scheduling gives students more time in class to ask questions and practice concepts. Barr and Parrett (1995) agreed the more time students have to develop positive relationships with teachers and students the more connection to school they will feel, and the more positive adult influence at-risk students receive the more successful they will be. The formation of positive relationships and the feeling of connection to school are vital for at-risk student success.

At-risk students have to learn how to be resilient and the appropriate ways to cope with the obstacles they face (Edward et. al, 2007). This suggests counselors and teachers find ways to empower at-risk students and help them to develop a positive outlook on life 
and learn the importance of being successful in school for their life after high school (Suh et al., 2007). To do this, educators need to foster the development of positive teacher relationships to help at-risk students build a connection to school (Barr \& Parrett, 1995, Edward et al.) A block schedule gives students more time to develop these relationships (Owings \& Kaplan, 2001). When at-risk programs facilitate the development of positive relationships and connections, students will begin to see a reason to come to school (McLaughlin \& Vachta, 1992; Suh et al., 2007).

Peer tutoring. Facilitating the formation of relationships and connections to school can be done by implementing programs that help at-risk students learn how to interact and communicate with others. One such program that has students interacting with each other is peer tutoring. Peer tutoring has been found to be an effective alternative intervention when implemented classroom wide (McLaughlin \& Vachta, 1992). Peer tutoring helps students develop positive relationships and gives students the opportunity to teach and interact with each other. It teaches students how to appropriately interact with others and learn material, because the person teaching usually learns the most. In this case, the students are teaching so they are learning more.

Edward et al. (2007) and Vaughn et al. (2007) suggested schools develop student mentoring programs and community service projects for at-risk students because it has been proven at-risk students benefit from participating in these activities. Peer-tutoring and mentoring programs were sought to be better than traditional approaches for at-risk youth. It was suggested these programs aim at teaching communication skills and coping skills for students at-risk of dropping out of high school. These programs help provide additional support and give students the opportunity to fulfill a commitment and 
accomplish a goal. The following paragraphs detail a study of a program that improved student achievement by using the theory of peer tutoring.

Kourea, Cartledge, and Musti-Rao (2007) conducted a study about a program designed to help at-risk students by using peer tutoring, students teaching each other. This study was conducted in an urban school setting as the authors contended students in urban areas had more obstacles to overcome in their education then their suburban peers did. The "total class peer tutoring" (Kourea et al., p. 95) program supposedly "accounts and compensates for family and sociocultural risk factors and prevents students' early academic failure" (Kourea et al., p. 95). This program aimed to help all children, regardless of their academic status.

The above study was conducted in a small Midwestern urban elementary school. The focus was a joint second/third grade class that included all students, students with and without disabilities. Half of the students were receiving special education instruction outside the regular classroom. Most of the students in the school were African American. The regular education teacher and the special education teacher were both trained in how to facilitate the peer tutoring with the regular education teacher being the main facilitator. Peer tutoring was implemented three times a week during 30 minute windows. The study focused on four aspects of reading education: "sight word acquisition, reading fluency, comprehension, and maintenance" (Kourea et al., 2007, p. 97). There were three assessments, the Woodcock-Johnson-III, the DORF Progress Monitoring Passages, and constructed paragraphs, used to determine if the peer tutoring had been successful. Parents and teachers completed a 4-point Likert questionnaire at the end of the study, and students completed an ordinal questionnaire at the end of the study. 
Kourea et al. (2007) found all participants in the study learned more sight words from peer tutoring than they did with traditional teacher led instruction. Reading fluency and comprehension increased for all students during the study, and all but one student maintained a high level of the sight words studied during peer tutoring. The teacher and parent surveys were returned with high markings for the peer tutoring program. The majority of students' responses on the survey were positive for the program; they felt the program helped them learn. The authors concluded "this study showed that total class peer tutoring is a viable instructional alternative for both general and special education teachers to support and meet the reading needs of minority and culturally diverse students" (Kourea et al., p. 106). Thus, establishing this could be an effective intervention for at-risk students.

Peer tutoring programs help students develop healthy relationships and can be a tool educators use when helping at-risk students identify with school and succeed (McLaughlin \& Vachta, 1992; Edward et al., 2007). In addition, student mentoring programs and student oriented community service projects help students form connections and feel a sense of accomplishment (Vaughn et al., 2007). Kourea et al. (2007) proved peer tutoring to be an effective tool in their study about peer tutoring with at-risk students. An alternative program that implements some type of peer tutoring will accomplish more than just improving academics.

Transitions. Many at-risk students have a difficult time transitioning from one learning experience to the next such as the transition from middle school to high school. This may be because they are losing the connections they formally had. Furthermore, transitions that happen after middle school are rougher on at-risk students. Therefore, 
intervention programs for at-risk students need to happen before high school (Vaughn, et al., 2007), and these programs need to help students transition to high school, (Owings \& Kaplan, 2001; Wheelock \& Miao, 2005).

Ezarik (2003) suggested initial at-risk programs focus on transitions for students, and these services be provided long term, as quick fixes do not exist. In a successful alternative middle school program in Wisconsin, teachers followed students to high school by following up on their progress and communicating with their current teachers. Since the start of the program, "the number of students failing one class has decreased from $23 \%$ to 5\%" (Woelfel, 2003, p. 47). Additionally, schools need to help at-risk students transition to the workforce (Barr \& Parrett, 1995). If at-risk programs stop at the building they are housed in and do not help students transition to the next building, the progress made comes to a halt. Students need to be supported in their transitions so they can keep the connections they have formed.

Child care programs. Alternative education programs at the secondary level that provide child care have been proven to be successful. It has also been found "having sex before age 15 significantly increased the possibility that a student would drop out of school" for all three at-risk groups (Suh et al., 2007, p. 201). To encourage students to finish their education after having a child, a child care facility at the school helps keep students in school. At the elementary level, providing child care before and after school has been proven to help at-risk students get the care they need (Barr \& Parrett, 1995). Child care centers help teen mothers keep their connection to school and graduate. They give elementary at-risk students a positive place to stay after school that enriches their learning. 
Variety of teaching methods. In addition to helping at-risk students form connections and transition from one learning experience to the next, alternative programs need to focus on improving academics. A variety of teaching methods were found to help promote academic achievement in at-risk youths such as cooperative learning, direct teaching instruction, and personalized instruction (McLaughlin \& Vachta, 1992). Carpentier (2007) conferred this when he stated "sometimes it takes many different instructional approaches before the right method for each child becomes apparent" (p. 9). He further suggested teachers used differentiated instruction (Flores \& Kaylor, 2007) in their classroom so the approach matches the "individual students rather than all students in a class or group" (Carpentier, p. 11). Implying the need for educators to vary their teaching methods because if a child is only exposed to one way of learning and this is not congruent with how he/she learns, he or she is set up for failure. A variety of teaching methods allows teachers to reach their students in multiple ways. Alternative programs need to use an array of proven teaching methods to reach the diverse population they serve.

Additional support during the school day. In addition to using multiple teaching methods, it has been found schools that are providing more support for at-risk students during the regular school day are seeing more improvement in the achievement of at-risk students (Ezarik, 2003). An example of this is a study conducted by Woelfel (2003). Woelfel researched six programs that were successful at helping at-risk middle school students. These programs were found to help struggling students turn things around academically and get back on track. One program found was a "double-dose" (Woelfel, p. 45) program at a middle school in Philadelphia. Students falling behind in mathematics 
and communication arts were scheduled for these classes twice a day. These students were grouped homogeneously and had the same teacher for these classes all three years at the middle school. Since the advent of the program in 1995, student promotion rates had increased $18.4 \%$ by the year 2000 . The additional support during the school day was helping these students become more successful in school. Additional support gives at-risk learners more time to master the material and prevents them from receiving low grades.

Extended day programs. Schools are limited by the number of hours they see students in a day. Adding on an optional program after the school day ends is one method educators have to get more time to work with students. School districts using extended learning programs for at-risk students were found to be having success decreasing drop out rates (Ezarik, 2003). A successful middle school alternative program found was an accelerated alternative program in Rhode Island. The program was designed for older middle school students; it allowed students to complete grades seven, eight, and nine in two years versus the traditional three years. The program was a comprehensive program in that it provided a range of services including a tutoring program on Saturdays and other activities for the youth after school, on the weekends, and during vacations (Woelfel, 2003).

A similar program proved successful for a middle school in Wisconsin. The school started an after school program to help at-risk students with their homework. In addition, the school offered participation in extracurricular activities as incentives to students that met certain academic requirements (Woelfel, 2003). These additional opportunities were giving students a positive place to be while at the same time helping them with their academics (Barr \& Parrett, 1995). 
Policies aimed at eliminating retention. In addition to developing programs, school leaders can develop policies aimed at improving graduation rates and improving student achievement. One common policy for students that fail is the requirement students are retained in the grade they failed. Retention has proven to be an ineffective way of improving student achievement (Bowman, 2005). Students retained in middle school are $90 \%$ more likely to drop out of school than their peers (Jimerson, Anderson, \& Whippel, 2002; Woelfel, 2003).

Ezarik (2003) found school districts with policies aimed at ending social promotion were having more success improving student achievement versus schools with strict retention policies. When district administrators are developing policies to address this problem, they need to use data to drive the policy and improvement programs (Wheelock \& Miao, 2005). Research has found schools that use multiple measures and assessments to determine if a child should be retained or promoted are improving student achievement while lowering the number of retentions.

Ezarik (2003) outlined some suggestions for educators to consider when developing policies and programs to eliminate retention while improving student achievement. It was first suggested educators not allow "grade 'repeats" (Ezarik, p. 38). When students are retained, they should have new educational experiences, not a repeat of one. Many times when a student is retained, they experience the same education again with no changes in instructional strategies or curriculum. "Many of us know that when students are retained, the only difference between their last and next year's performance is the teacher, the teacher's bag of tricks (ways of breaking through), patience, commitment to that youngster, and a change in the environmental ambience" (Carpentier, 
2007, p. 9). Educators could consider having children only repeat part of a grade or have classrooms structured by skill level not age level. It has been found just putting a child back in the grade they failed is not going to improve that child's achievement.

A study conducted to determine what effective alternative programs were doing found a middle school in Michigan used a no failing strategy to improve student performance. Students were not allowed to turn in incomplete work; teachers assigned incomplete grades instead of failing grades. Students received help with homework through an after school homework club and received rewards when grades improved (Woelfel, 2003). This was an example of a school district that eliminated their retention policy and was having success. Strict retention policies do not help school districts decrease drop out rates and improve student achievement (Jimerson et al., 2002). Only when school official eliminate these policies and focus on the real problem will achievement increase.

Summary. Successful intervention programs for at-risk students have several characteristics. First, they facilitate the development of positive relationships and connections to school. They teach at-risks students how to be resilient and learn the importance of school (Barr \& Parrett, 1995; Edward et. al, 2007, Suh et al., 2007). Second, peer tutoring helps students form these positive relationships while helping students improve academically (Kourea et al., 2007; McLaughlin \& Vachta, 1992). Third, they help students transition from one learning experience to the next (Owings \& Kaplan, 2001; Vaughn et al., 2007). Fourth, many at-risk programs at the high school level provide child care for students and at the elementary level provide care before and after school (Barr \& Parrett). Fifth, effective programs utilized a variety of teaching methods 
including cooperative learning, direct instruction, and personalized instruction (Carpentier, 2007; McLaughlin \& Vachta). Sixth, they are giving at-risk students additional support during the school day (Ezarik, 2003). Seventh, many successful programs give students additional support outside of the school day with extended day programs (Barr \& Parrett; Ezarik, 2003). Seventh, policies aimed at eliminating retention are in place at high achieving schools (Carpentier; Ezarik; Woelfel, 2003). School leaders need to use a combination of these proven characteristics when developing alternative programs. In the next section, studies of effective alternative programs are detailed. Studies of Effective Middle School and Elementary Alternative Programs

There have been several studies done to determine what type of alternative program structure is best for improving academic achievement for at-risk students. A variety of results have been found. Suh, Suh, and Houston (2007) found students who dropped out of school differed among the three groups of at-risk students in their study and were affected differently. Therefore, it was suggested at-risk programs be structured differently based on the characteristics of the group. The following studies give insight into how successful alternative programs can be structured.

Owings and Kaplan (2001) conducted a study to determine what high school principals could do to facilitate improvement in student achievement. They presented several recommendations derived from their findings. They first recommended high school administrators give teachers a common planning time so they could collaborate together, conference with parents about student progress together, and better keep track of student attendance; because all three of the aforementioned things have been proven to 
directly correlate to at-risk student success (Barr \& Parrett, 1995; McLaughlin \& Vachta, 1992; Vaughn et al., 2007).

Wheelock and Miao (2005) suggested structuring high schools into small communities of learning to help teachers keep track of their students better. In addition, Owings and Kaplan recommended leaders focus on best practices with teaching objectives aligned to curriculum and assign at-risk students to veteran teachers (Carpentier, 2007; McLaughlin \& Vachta, 1992). The reason being these teachers have the most experience in dealing with low performing students and have a repertoire of skills to use with them (Owings \& Kaplan, 2001).

It was noted classroom assessments should be aligned to achievement tests in content and in style. Many students need to practice the structure of a test to perform well on the test. These intervention strategies were suggested for secondary administrators, high school and middle school, to consider when leading their school in improving student achievement for all learners (Owings \& Kaplan, 2001).

More alternative middle school programs are being developed as research has shown the earlier educators help at-risk students, the more likely they are to succeed (Vaughn et al., 2007). Following is a discussion about three such middle school programs. Education leaders in an Indiana middle school used a conglomeration of strategies in their middle school alternative program. The program used a three pronged approach: multiple strategies for success, adequate time allowed for all students to complete assignments, and connection with at-risk students (Barr \& Parrett, 1995; McLaughlin \& Vachta, 1992; Woelfel, 2003). This combined effort helped decrease the number of failing students by 62 in one year. 
Educators in a Kansas middle school also hit at-risk students from multiple directions (Barr \& Parrett; McLaughlin \& Vachta; Woelfel). Students who failed a class were required to attend summer school and master the objectives written by their teachers. They received more support the next academic year and were allowed to reenter their regular grade class when educators felt they were ready (Ezarik, 2003; Woelfel, 2003). These two middle school programs identified by Woelfel both focused on the whole child and developed connections for students (Edward et al., 2007). These interventions were a "hallmark of commitment by administrators and teachers to give students a second chance at success" (Woelfel, p.48).

Schweiker-Marra and Pula (2005) conducted a three year mixed case study of atrisk middle school students placed in a low-tracked homogenous program. "The perceived advantage of tracking is that it better serves students by reducing the range of academic diversity so low achievers receive remediation and high achievers are not slowed down" (Vaughn et al., 2007, p. 303). The purpose of the study was to determine if student academic achievement improved in this program, and, if so, what components of the program were facilitating this success.

The research was driven by the fact the number of at-risk students was increasing due to the rise of single family homes (Barr \& Parrett, 1995) and homes of abuse and the impact they are having on our society. According to Schweiker-Marra and Pula (2005), "80 percent of graduating seniors left school without writing skills adequate for employment and that fewer than 50 percent of those students could perform moderately complex tasks needed for low paying jobs available" (Schweiker-Marra \& Pula, p.34), implying the necessity for schools to develop more effective programs to help these at- 
risk students succeed and improve their academic achievement (Barr \& Parrett; Vaughn et al., 2007).

The study was conducted in a middle school with a population of 500 students located in the Southeastern part of the United States. Student social classes ranged from lower class to upper class. Fifth and sixth grade classes were heterogeneously mixed, but when students entered the seventh grade they were tracked by their academic status. Atrisk students were placed into a separate program than their peers. The students were identified as at-risk based on their performance on the Comprehensive Test of Basic Skills.

The focus of the at-risk classes was on basic skills in mathematics and communication arts (McLaughlin \& Vachta, 1992). Concepts were reinforced through a variety of methods including teacher instruction, computer drills, and hands on work with manipulatives (McLaughlin \& Vachta). As the years progressed, cooperative learning and hands on instruction became the predominant teaching methods used. There was a strict classroom management plan in place that included rewards for student progress. The students were tested at the end of every year with the Stanford Achievement Test, ninth edition. Additionally, teachers were interviewed and observed and pertinent documents such as lesson plans were collected (Schweiker-Marra \& Pula, 2005).

It was found, by using a two-way ANOVA test, the number of students testing into the lowest quartile in the Stanford Achievement Test, ninth edition, decreased every year over the three years. Through teacher interviews it was also found all the teachers in the program felt "student attitudes strongly affect both academic performance and behavior" (Schweiker-Marra \& Pula, 2005, p. 40). The researchers, therefore, concluded 
this low-tracked homogeneous program for at-risk students was effective at increasing student achievement due to the reduced number of students testing into the lowest quartile on the Stanford Achievement Test, ninth edition. The researchers also concluded the reward system used in the program did help improve student's behavior and selfesteem resulting in improved academic achievement (Barr \& Parrett, 1995).

Furthermore, they found veteran teachers with experience working with at-risk youth are essential for low-tracked programs to be successful (Owings \& Kaplan, 2001). This intervention program was found to be successful at improving student achievement and attitudes in at-risk middle school students. It could be a strategy educators use to improve student achievement in all student groups. These three alternative middle school programs are examples of the success administrators experience when they develop policies to end retention, and instead focus on interventions for at-risk students (Ezarik, 2003; Woelfel, 2003).

If it has been found that the earlier intervention programs are presented to at-risk youth, the more likely they are to succeed in school, it would make sense that intervention programs start in elementary school. "Research on programs for students at risk has indicated that the most fruitful time to provide remediation is during the preprimary and early primary grades" (Vaughn et al., 2007, p. 303). One such elementary program has been developed and is being implemented in elementary schools around the country. The reading recovery program has been found to be a successful intervention reading program for children in elementary school. Students who are in the first grade that are low achieving in a reading recovery classroom receive individual tutoring for 30 minutes a day until they are reading at grade level or have completed a certain number of 
sessions. This program aims to "prevent reading failure" (Vaughn et al., p. 304). The earlier students learn basic skills, such as reading, and get on grade level, the less likely they are to fail (McLaughlin \& Vachta, 1992).

Summary. Whatever alternative programs school districts develop, they should incorporate a variety of proven effective strategies. As the research has found, "there is no one reason why students drop out" (Vaughn et al., 2007, p. 297). Woelfel (2003) and Schweiker-Marra and Pula (2005) illustrated this in their research about effective middle school alternative programs. Additionally, it has been found successful programs should be implemented at the elementary level. Programs at the secondary school level are beneficial, but they are only reactive. Earlier programs allow educators to be preventive. Vaughn et al. presented an example of this in their research about the reading recovery program. Students at-risk are being identified earlier and earlier as the focus has shifted to helping these children at a younger age (Barr \& Parrett, 1995). The increasing number of at-risk students is putting tension on the education system, and if not properly addressed, several long term consequences could arise. The following section delineates the consequences that have surfaced from the large number of at-risk students and future ones that could exist if the problem is not dealt with effectively.

\section{Long Term Consequences}

When planning for the future, school leaders have to look at the long term consequences of the increasing number of at-risk students. Retention and social promotion policies are being redefined as schools are placed under more mandates (Vaughn et al., 2007). There are an increasing number of students being retained in the ninth grade, and this is becoming costly for school districts (Russo, 2005; Wheelock \& 
Miao, 2005). As a result, educators are looking for ways to identify at-risk students earlier and new ways to help these students (Sprague \& Walker, 2005; Vaughn et al). This will all have to be done under tight budgets (Barr \& Parrett, 1995). The following paragraphs detail the long-term consequences educational leaders will have to face and changes that need to be made.

The current trends of either social promoting or retaining at-risk students are costly, ineffective methods of dealing with these students. Retention and social promotion have been show to not increase academic achievement (Bowman, 2005; Ezarik, 2003; Jimerson et al., 2002; Thompson \& Cunningham, 2000; Woelfel, 2003), and "as many as 15 percent of students repeat a grade each year in the United States" (Leckrone \& Griffith, 2006, p. 53). The theory behind retention is by having a student repeat a grade they will have additional time to master the material. However, this is not happening in the majority of students retained.

Retention has been positively correlated with a student's chance of dropping out of school and the number of discipline problems at school. If a student is retained, he or she is more likely to be a discipline problem in the classroom and drop out of school. In some cases it has been found students make more progress if they are socially promoted to the next grade than if they are retained in that grade (Owings \& Kaplan, 2001). "Study after study concludes that, when retained, students then are compared with classmates with similar deficiencies who have been promoted. It is that second group that generally performs better than their classmates who remained behind" (Carpentier, 2007, p. 9).

Although students who were socially promoted do achieve more than retained students, it is not a good solution to the problem. Socially promoted students are not held 
accountable for their education, and ultimately as a result, do not see a reason why they have to put forth quality effort at school because they passed before without effort. According to Wheelock and Miao (2005), retained and social promoted students are not held accountable for their work. These methods do not motivate students to do better the next year. Social promotion policies allow students to graduate without having the requisite knowledge needed for the workforce. Retention and social promotion are ineffective ways of dealing with at-risk students (Owings \& Kaplan, 2001).

Social promotion and retention do not improve student achievement and are costly to the American public as these students do not enter society adequately prepared. Colleges are spending more money to offer remedial classes to these children (Mattson, 2007), and the "lack of educational training and job preparation results in higher unemployment rates and lower pay among dropouts" (Vaughn, et al., 2007, p. 296). Educators have to develop new ways "to promote student learning and success in the school setting" (Leckrone \& Griffith, 2006, p. 55).

High stakes testing and mandates have increased the number of students being retained (Leckrone \& Griffith, 2006). This number will continue to grow if school leaders do not adjust the curriculum and instruction to meet the needs of at-risk students. As a result, some researchers have concluded that about one third of today's youth are dropping out of high school and not receiving a high school diploma. United States employers recently surveyed indicated $75 \%$ of organizations and business are faced with a shortage of workers that are qualified. They are investing a significant amount of money to train these unqualified workers (Vaughn et al., 2007). Industry is competing on 
a global scale, and as a result, American companies are seeking out qualified workers in other places (Barr \& Parrett, 1995).

Wheelock and Miao (2005) argued national graduation rates are declining and school districts are not doing enough to prevent this problem. As a result, there are a growing number of students being retained in the ninth grade creating a bottleneck of students in America's freshman class. Students are increasingly having a difficult time transitioning from the eighth grade to high school, and more students are flunking ninth grade and having to repeat it. The trend is more dramatic for African American students and Latino students than for Caucasian students. The authors claimed school leaders have to do more than develop policy as evidenced by the passage of a national education goal in 1994 that stipulated by 2000 all schools have a graduation rate of 90 percent. This goal was not met, and graduation rates continued to decline. Schools were not held accountable with this act. Following is an example of a school district that had a strict retention policy (Russo, 2005). The consequences that arose as a result of this policy are presented.

The public school system of Chicago had an intensive retention policy in place. Students failing to meet minimum standards on the state standardized test, the Iowa Basic Skills Test, were required to attend summer school for remediation and also faced possible retentions. There have been 10,000 students in Chicago public schools held back since 1997 , and it cost the district around $\$ 8,400$ a year to educate a child (Russo, 2005). This was a huge economic burden on the school district and taxpayers. Many retained children received the same education they did the year before; no adjustments had been made, and they were not exposed to new learning experiences (Carpentier, 2007; Ezarik, 
2003). Furthermore, the minimum score needed to be promoted to the next grade had been changed several times and some students were given waivers and passed even though they had failing test scores (Russo). Students were still graduating with a lack of basic skills (Vaughn et al., 2007). This example illustrates how retention is not working to improve student achievement. Not only is it not working, it is costly for schools. Schools are going to have to provide more interventions to improve student success of poor performing students and develop ways to prevent students from becoming at-risk (Barr \& Parrett, 1995; Vaughn et al.). To prevent this problem, at-risk students need to be identified earlier.

To identify at-risk students earlier, school districts are going to have to centralize data so counselors and teachers can see a trend in performance before it is too late, as evidenced by the ninth grade bottleneck (Wheelock \& Miao, 2005). Educational leaders need to quit ignoring the ninth grade bottleneck and make it visible to the public. They should use this data positively to identify at-risk students earlier (Sprague \& Walker, 2005). Discipline records, grades, and evaluations should become accessible to educators quickly. "Schools substantially underutilize the technology that has developed over the past several decades in the area of behavioral screening and early detection of school adjustment problems" (Sprague \& Walker, p. 146). Screening children to determine if they are at-risk will need to begin in elementary school (Vaughn et al., 2007); teachers will need to be trained to look for characteristics of at-risk children and how to implement appropriate early interventions.

To overcome the obstacles at-risk students and their families face, schools have developed into "full-service schools" (Vaughn et al., 2007, p. 305). These schools 
"served as a hub of educational, psychological, physical, financial, social, and healthrelated services for a community" (Vaughn et al., p. 305). The idea is to have these things accessible for students and parents so education can become a priority for students. However, extensive funding is required for schools to do this. They either have to apply for grants and aid or proportion a part of their annual budget for these services (Vaughn et al.).

To improve student achievement for at-risk students, schools are going to have to spend more money on alternative interventions. Under the current model of funding for schools, affluent communities can spend more money educating children because they have more money in their budget than poorer schools. However, poor school districts have more at-risk students to educate. "The existence of poverty in the home and community is too often matched by poverty in the school setting, which directly contributes to the failure of so many at-risk youth" (Barr \& Parrett, 1995, p. 38). The federal and state legislatures are going to have to change how they allocate funds in schools.

There are several consequences that arise from the increased number of at-risk students in the United States. Leaders in education will have to redefine retention and social promotion polices as neither have proved to be effective in improving student achievement (Ezarik, 2003; Jimerson et al., 2002; Woelfel, 2003); in fact, students who are retained are more likely to drop out (Owings \& Kaplan, 2001). "Studies have shown that 78 percent of student who drop out have been retained" (Leckrone \& Griffith, 2006, p. 54). These ineffective policies are resulting in an increased number of students in the ninth grade (Wheelock \& Miao, 2005) and are costing school districts a lot of money 
(Bowman, 2005; Russo, 2005). To conquer this crisis, it has been recommended schools implement more effective alternative programs and identify at-risk students' earlier (Vaughn et al., 2007). To do this, Sprague and Walker (2005) suggested schools centralize data. To eliminate the barriers, many at-risk families face Vaughn et al. thought schools should become hubs that offer all the services these families need. For all of this to happen, the way education is funded will need to change (Barr \& Parrett, 1995). Atrisk education has become a primary focus for educational leaders and is requiring schools to change policies, change the way they allocate their budget, and restructure.

\section{Summary}

In chapter two, literature about at-risk students and alternative programs was reviewed. Five topics emerged, and the literature review was structured around them. First, a summary of legislation was reviewed. Legislation for at-risk students was first passed in 1954. That same year a redefining moment happened in public education with the ruling in Brown v. Board of Education of Topeka, Kansas (Barr \& Parrett, 1995). In the present day, educators are working to meet the demands of the No Child Left Behind Act of 2001 (Vaughn et al., 2007). Second, characteristics of at-risk students were detailed. These were split into school factors and family factors. At-risk students are students who are failing school and are likely to dropout of school (McLaughlin \& Vachta, 1992). They have little support at home and often come from minority and poor families (Barr \& Parrett). Third, characteristics of effective intervention programs were identified. There were many characteristics identified, and it was suggested educators use an assortment of them when developing alternative programs (Ezarik, 2003). Forth, studies of effective middle school and elementary alternative programs were reported. 
The sooner educators identify and help at-risk youth, the more likely these students are to succeed (McLaughlin \& Vachta, Ezarik, Vaughn et al.) Fifth, long term consequences were addressed. The education of at-risk students is costly, but it is even more costly for school and taxpayers if the problem is ignored (Barr \& Parrett, Russo, 2005; Wheelock \& Miao, 2005).

Chapter three details the design of the mixed study of an alternative middle school. Research questions, hypotheses, and the research design are delineated. The results of the quantitative piece and the qualitative piece are presented in chapter four. Chapter five discusses the findings of the quantitative piece and the qualitative piece and presents a review of the study. Implications for educators and recommendations for further research are included. Appendices of the consent for the guardians (Appendix A), the consent form for the students (Appendix B), and the interview protocol (Appendix C) are available for review following the reference list. 


\section{CHAPTER THREE \\ RESEARCH DESIGN AND METHODOLOGY \\ Introduction}

School districts have been under pressure to improve student performance as federal and state legislatures have increased the number of accountability requirements for school districts. As a result, many at-risk programs have been developed as a response to the requirements (Woelfel, 2003). One such program developed by a school district was entitled the "academic recovery program;" this program consisted of smaller classes taught by the same teacher. The academic recovery classes were smaller communication arts and mathematics classes designed to give struggling students a more one-on-one experience and develop a connection to the school (Owings \& Kaplan, 2001). The goal was to help students get academically back on grade level before they entered high school. The program was designed for middle school students two years or more behind academically, who did not qualify for special education, and who did not have discipline issues in the classroom. Students qualified for the classes through principal, counselor, and teacher recommendation.

This study was proposed as a possible tool for the school district to use when evaluating the middle school academic recovery program (Patton, 1997). The district was investing a significant amount of money into the program, and many times when buildings in the district had to reduce the number of staff, academic recovery teachers were the first personnel moved. Academic recovery classes were offered if teachers were available to teach these classes after the assignment of teachers to required courses. The decision was based on the number of full-time teachers assigned to the school from the 
central office of the school district. This number was decided by the projected enrollment of the school. This resulted in an inconsistency of the program and the elimination of the program at certain school sites.

The purpose of this study was to determine how effective an academic recovery program at the middle school level was in improving student academic achievement, using scores on state assessments as the measure of success. The study compared student test scores in communication arts and mathematics before and after the implementation of the program for students in the academic recovery program classes and students that qualified for the classes but not enrolled in them. Additionally, the purpose of this study was to determine what the student perceptions and experiences were associated with the academic recovery program and to determine if the program resulted in a positive change of thinking about school for the students (Owings \& Kaplan, 2001).

The purpose of chapter three is to detail the research design and methodology. First, research questions are presented followed by the corresponding hypotheses. Then an overview of the mixed study is outlined detailing the design of the study and the data collection techniques. Lastly, is a discussion of how the data were analyzed, followed by a conclusion.

\section{Research Questions}

Within the context of the study, the following research questions were addressed:

1. What was the effect of academic recovery classes on the state assessment, as measured by the Missouri Assessment Program (MAP) test in communication arts, on middle school students (grades 6, 7, and 8) enrolled in academic recovery classes? 
2. What was the effect of academic recovery classes on the state assessment, as measured by the MAP test in mathematics, on middle school students (grades 6, 7, and 8) enrolled in academic recovery classes?

3. What was the comparison of middle school student test scores, as measured by the communication arts of the MAP test, of middle school students (grades 6, 7, and 8) in academic recovery classes and students qualified for academic recovery classes but not enrolled in academic recovery classes?

4. What was the comparison of middle school student test scores, as measured by the mathematics component of the MAP test, of middle school students (grades 6 , 7, and 8) in academic recovery classes and students qualified for academic recovery classes but not enrolled in academic recovery classes?

5. What were the perceptions of middle school student's (grades 6, 7, and 8) experiences in academic recovery classes?

\section{Research Hypotheses}

The following research hypotheses which related to the stated research questions were also examined:

Hypothesis 1: Student test scores in communication arts as measured on the MAP improved (alpha level .05) for students in academic recovery classes.

Hypothesis 2: Student test scores in mathematics as measured on the MAP improved (alpha level .05) for students in academic recovery classes.

Hypothesis 3: Students in academic recovery classes had greater increases in 
communication arts test scores (alpha level .05) as measured by the MAP than students that qualified for academic recovery classes but were not enrolled in the classes.

Hypothesis 4: Students in academic recovery classes had greater increases in mathematic test scores (alpha level .05) as measured by the MAP than students that qualified for academic recovery classes but were not enrolled in the classes.

\section{Design of the Study}

A mixed design with both quantitative and qualitative approaches was used in this study. The addition of a qualitative part with the quantitative part allowed "the lived experiences of the participants" to be studied (Heppner \& Heppner, 2004, p. 137). The quantitative and qualitative pieces were studied separately because they each focused on different aspects of the academic recovery program. The quantitative piece "describes the "what"” (Glanz, 1998, p. 92) as the qualitative piece "describes the 'how"” (Glanz, p. 92). The quantitative part of the study described what the gains in student achievement were as measured by the MAP (Field, 2005), and the qualitative part of the study described how the students viewed the program and their experiences associated with the program (Merriam, 1998).

The quantitative part of the study compared student communication arts and mathematics test scores from the MAP before and after the student's enrollment in academic recovery classes. The previous year MAP scores (2006) were compared to the present year MAP scores (2007). Student test scores on the MAP of those who qualified for academic recovery classes, but were not enrolled in them were compared to students enrolled in academic recovery classes (Field, 2005). Gatekeeper consent from the school 
district was obtained, and the researcher received student scores without identifying information attached to them. Approval and support for the research was obtained from the school district (Fink, 2006; Seidman, 2006).

The qualitative part of the study was in the form of one focus group interview, one interview, and questionnaires. These interviews were conducted with students who were in academic recovery classes in middle school. Gatekeeper consent was obtained from the school district to interview the participants (Seidman, 2006). Additionally, the guardians consented to the interview by signing a consent form (Fink, 2006; Appendix A), and the students were given a youth consent script informing them of their rights (Appendix B). The interviews were arranged at a time convenient for the participants. The participants were asked open ended questions developed to explore student perceptions of the program and their experiences with the program. Clarifying questions were asked to elicit further details and clarify misunderstandings (Seidman).

\section{Population and Sample}

Population. The school district in this study was an urban school district in Missouri with a total enrollment of 24,258 students. Caucasian students comprised $87.5 \%$ of the population, African American students comprised 6.6\% of the population, Hispanic students comprised $2.9 \%$ of the population, Asian students comprised $2.3 \%$ of the population, and Indian students comprised $0.6 \%$ of the population. The school district reported a free/reduced lunch rate of $42.6 \%$ which was similar to the state average of $41.8 \%$. All of the aforementioned demographic data was reported by the school district during the fall of 2006 (Missouri Department of Elementary and Secondary Education, 2006c). 
The population for this study was middle school students, in grades sixth, seventh, and eighth, enrolled in a middle school academic recovery program class or qualified to be in a middle school academic recovery class. The three schools in the study were midsized schools that ranged in size from 400 to 700 students. Students in the academic recovery classes experienced smaller class sizes than their peers and often had the same teacher for communication arts and mathematics. Class sizes ranged from five to ten students. A teacher's aide often was in the room to assist the teacher. The students in the comparison group experienced a traditional middle school classroom setting. Class sizes for these students ranged from 20 to 30 and they had different teachers for communication arts and mathematics.

Table 1 outlines MAP data for the spring of 2006. In 2006, all students in grades six, seven, and eight in the state of Missouri were required to take the MAP Tests in communication arts and mathematics. The table details the results for the district, the state, and the expectations towards meeting the goal of all students proficient and advanced in communication arts and mathematics by the year 2014. The school district performed better than the state average in 2006 and met the No Child Left Behind goal for all grades and all subjects. However, the district failed to meet some of the subgroup goals in 2006 (Missouri Department of Elementary and Secondary Education, 2008a). 
Table 1

Percentages of Mathematics and Communication Arts Test Scores on the MAP 2006

\begin{tabular}{|c|c|c|c|c|c|c|c|}
\hline & & District & & Missouri & & Expected by & CLB* \\
\hline Grade & MAP Level & $\mathrm{CA}$ & Math & $\mathrm{CA}$ & Math & $\mathrm{CA}$ & Math \\
\hline \multirow[t]{5}{*}{6} & Advanced & 16.4 & 17.9 & 10.8 & 9.7 & & \\
\hline & Proficient & 38.3 & 42.9 & 32.2 & 34.9 & 34.7 & 26.6 \\
\hline & Basic & 36.9 & 33.6 & 45.2 & 44.3 & & \\
\hline & Below Basic & 8.4 & 5.6 & 11.8 & 11.1 & & \\
\hline & LND & 0.3 & 0.2 & 0.9 & 0.5 & & \\
\hline \multirow[t]{5}{*}{7} & Advanced & 20.4 & 17.1 & 12.6 & 10.5 & & \\
\hline & Proficient & 37.2 & 40.0 & 31.3 & 33.3 & 34.7 & 26.6 \\
\hline & Basic & 34.3 & 33.2 & 42.4 & 38.8 & & \\
\hline & Below Basic & 8.2 & 9.7 & 13.7 & 17.5 & & \\
\hline & LND & 1.0 & 0.4 & 1.7 & 0.8 & & \\
\hline \multirow[t]{5}{*}{8} & Advanced & 24.2 & 21.7 & 15.3 & 12.5 & & \\
\hline & Proficient & 32.4 & 35.4 & 27.2 & 28.2 & 34.7 & 26.6 \\
\hline & Basic & 36.8 & 30.9 & 48.5 & 38.2 & & \\
\hline & Below Basic & 6.6 & 12.0 & 9.0 & 21.2 & & \\
\hline & LND & 0.5 & 0.4 & 1.2 & 0.9 & & \\
\hline
\end{tabular}

Note. $\mathrm{CA}=$ Communication Arts. NCLB $=$ No Child Left Behind. LND $=$ Level Not Determined.

Information from Missouri Department of Elementary and Secondary Education, 2007a; Missouri

Department of Elementary and Secondary Education, 2006b; Missouri Department of Elementary and

Secondary Education, 2006d.

*These scores are the number of students tested into advanced and proficient together. 
Table 2

Percentages of Mathematics and Communication Arts Test Scores on the MAP 2007

\begin{tabular}{|c|c|c|c|c|c|c|c|}
\hline & & District & & Missouri & & Expected by & CLB* \\
\hline Grade & MAP Level & $\mathrm{CA}$ & Math & $\mathrm{CA}$ & Math & $\mathrm{CA}$ & Math \\
\hline \multirow[t]{5}{*}{6} & Advanced & 15.5 & 18.2 & 12.1 & 12.6 & & \\
\hline & Proficient & 36.4 & 40.6 & 32.3 & 36.0 & 42.9 & 35.8 \\
\hline & Basic & 40.3 & 34.4 & 44.4 & 40.2 & & \\
\hline & Below Basic & 7.8 & 6.8 & 11.3 & 11.2 & & \\
\hline & LND & 0.4 & 0.2 & 0.7 & 0.4 & & \\
\hline \multirow[t]{5}{*}{7} & Advanced & 18.7 & 18.6 & 12.0 & 12.1 & & \\
\hline & Proficient & 38.4 & 40.6 & 33.6 & 33.7 & 42.9 & 35.8 \\
\hline & Basic & 34.5 & 31.1 & 41.3 & 37.3 & & \\
\hline & Below Basic & 8.4 & 9.6 & 13.1 & 16.8 & & \\
\hline & LND & 0.9 & 0.2 & 1.3 & 0.6 & & \\
\hline \multirow[t]{5}{*}{8} & Advanced & 22.9 & 23.1 & 15.0 & 14.4 & & \\
\hline & Proficient & 30.7 & 31.2 & 27.5 & 27.2 & 42.9 & 35.8 \\
\hline & Basic & 41.2 & 33.2 & 48.8 & 36.9 & & \\
\hline & Below Basic & 5.2 & 12.5 & 8.7 & 21.6 & & \\
\hline & LND & 0.6 & 0.3 & 1.0 & 0.8 & & \\
\hline
\end{tabular}

Note. $\mathrm{CA}=$ Communication Arts. NCLB $=$ No Child Left Behind. LND $=$ Level Not Determined.

Information from Missouri Department of Elementary and Secondary Education, 2007a; Missouri

Department of Elementary and Secondary Education, 2007c; Missouri Department of Elementary and

Secondary Education, 2007d.

*These scores are the number of students tested into advanced and proficient together. 
Table 2 outlines MAP data for the spring of 2007. In 2007, all students in grades six, seven, and eight in the state of Missouri were required to take the MAP Tests in communication arts and mathematics. The table details the results for the district, the state, and the expectation towards meeting the goal of all students proficient and advanced in communication arts and mathematics by the year 2014. The school district performed better than the state average in 2007 and met the No Child Left Behind goals for all grades and all subjects. However, it failed to meet some of the subgroups goals in 2007 (Missouri Department of Elementary and Secondary Education, 2008a).

The Missouri Department of Elementary and Secondary Education has set benchmarks for schools to attain each year to meet the requirements of the No Child Left Behind Act of 2001. Table 3 outlines the benchmarks school districts must attain in communication arts and mathematics in each subgroup population in the school district to make Adequate Yearly Progress.

The participants for the interviews were middle school students currently enrolled in academic recovery classes. The focus group interview had four students participate. This allowed for effective dialogue between the students (Krueger \& Casey, 2000). An interview with one student was also conducted, and two students filled out questionnaires which consisted of the same questions asked in the interviews (Appendix C). 
Table 3

Summary of Benchmarks for the No Child Left Behind Act of 2001 for School Districts in the State of Missouri

\section{Communication Arts Mathematics}

2006

34.7

42.9

51.0

59.2

67.4

75.5

83.7

91.8

100.0
26.6

35.8

45.0

54.1

63.3

72.5

81.7

90.8

100.0

Note. Information from Missouri Department of Elementary and Secondary Education, 2007a.

Sample. A comprehensive sample of twenty-one student records was used for research questions one, two, three, and four in the quantitative piece of this study (Field, 2005). Student records for students in the academic recovery classes obtained were all assigned a number in the order they were received. All student records obtained did not contain any identifying information (Fink, 2006). A comprehensive sample of thirty-one student test scores was used for the comparison of test scores on the state achievement test, the MAP. Each school site liaison sent a comparable list of students, without 
identifying information (Fink), which qualified for academic recovery classes but were not enrolled (Heppner \& Heppner, 2004).

A convenience sample was used for the qualitative piece of this study (Merriam, 1998). A typical sample was used to select the participants for the focus group interviews and interview. A typical sample was used to get an idea of what the "average person" (Merriam, p. 62) experienced in the academic recovery program and what their perceptions were of the program. Since the goal was to determine what the perceptions and experiences were of the average participant in the study, a convenience sampling approach was used. Students were selected if they returned the consent forms (Appendix A; Appendix B). These students were from three sites in the district; a focus group at one site was conducted, an interview at one site was conducted, and two questionnaires were filled out by students at the third site.

\section{Data Collection and Instrumentation}

Quantitative data for the study was obtained through the school district. Quantitative data consisted of student scores in communication arts and mathematics on the MAP Test. Qualitative data for the study was obtained through a focus group interview of academic recovery students, an interview with an academic recovery student, and questionnaires filled out by academic recovery students (Krueger \& Casey, 2000).

Approval from the school district was sought through the central office of the school district (Heppner \& Heppner, 2004). Then, Institutional Review Board (IRB) approval was sought for the quantitative and qualitative parts of the study (Fink, 2006; Seidman, 2006). In the spring of 2008, counselors from each participating site compiled a 
list of all students enrolled in the academic recovery classes at their school site by school ID number. Counselors also compiled a list of students by school ID number who qualified for academic recovery classes, but for various reasons were not enrolled in them. These student numbers were sent to the central office. A person from central office returned a list of scores to the researcher. The test scores used were from the MAP Tests students took in April 2006 and April 2007 in communication arts and mathematics. All information from the student records was obtained without any identifying information (Fink, 2006).

The qualitative part of the study consisted of one focus group interview, one personal interview, and two questionnaires. The interviews were conducted in the spring of 2008 with students enrolled in academic recovery classes or previously enrolled in them. The questionnaires were also filled out in the spring of 2008 by students in academic recovery classes. The IRB proposal addressed the qualitative piece and stipulated a consent form (Appendix A) would be filled out by the participant's guardians, and the participants would be given a youth consent form (Appendix B) after approval from the cooperating school district was granted (Fink, 2006; Seidman, 2006). Guardians and students consented to both the focus group interviews and the questionnaires. A multiple-category design was used for the focus groups. One focus group with four participants was conducted, an interview with one participant was conducted, and two questionnaires were returned that consisted of the same questions asked in the interviews (Appendix C). The interviews continued until a saturation of the ideas became apparent (Krueger \& Casey, 2000). 
Participants in the interview were purposefully sampled with the goal of discovering student perceptions of the academic recovery program and their experiences with the program (Merriam, 1998). An interview protocol (Appendix C) was designed that consisted of open ended questions. Probing questions were used to clarify information and misunderstandings (Seidman, 2006).

The focus group interview and the personal interview were taped and transcribed verbatim (Seidman, 2006). Extensive field notes were taken by the researcher to allow for triangulation of the data (Emerson, Fretz, \& Shaw, 1995; Merriam, 1998). The questionnaires were also transcribed verbatim. The fieldnotes and documents were gathered and analyzed in conjunction with interviews to identify emergent themes. After all interviews were conducted and transcribed and questionnaires transcribed, the researcher utilized an evolving, open coding strategy (Merriam) to identify categories and sort interview transcripts and documents.

\section{Missouri Assessment Program}

The achievement test selected for this study was the Missouri Assessment Program (MAP) Test. The MAP Test was designed to measure student progress towards achieving the Show-Me Standards. The Show-Me standards were 73 academic standards developed and adopted by the Missouri State Board of Education in 1996. The MAP test in communication arts and mathematics was given to all students in grades 3-8 in the spring of 2006 and the spring of 2007. The communication arts test was given to high school juniors, and the mathematics test was given to high school sophomores in the spring of 2006 and the spring of 2007. 
The MAP Test consisted of three types of questions: (a) selected response questions, (b) constructed response questions, and (c) performance event questions. Students selected the correct answer from a list of answer choices on selected response questions. Students constructed their own answers on constructed response questions and performance event questions. Performance event questions were more complex than constructed response questions and required the students explain their thinking in detail (Missouri Department of Elementary and Secondary Education, 2005a).

Selected response questions were scored on a one point scale, constructed response questions were scored on a two point scale, and performance event questions were scored on a three point scale by trained graders. Totals were added and students were placed into five categories: (a) below basic, (b) basic, (c) proficient, (d) advanced, and (e) level not determined. Level not determined scores were reported when students had such profound disabilities that a test could not be given, a student did not take a test, a student cheated on the test, or a student did not answer one question on one section of the test. Reports given to the school district included an achievement level, a national percent rank, and a raw score for each content standard (Missouri Department of Elementary and Secondary Education, 2006a).

The sixth grade communication arts MAP Test consisted of 47 selected response questions, eight constructed response questions, and no performance event questions. The seventh grade communication arts MAP Test consisted of 51 selected response questions, eight constructed response questions, and one performance event question. The eighth grade communication arts MAP Test consisted of 51 selected response questions, eight constructed response questions, and no performance event questions. All questions were 
aligned to the state Grade Level Expectations (GLEs) in communication arts (Missouri Department of Elementary and Secondary Education, 2005a).

The sixth grade mathematics MAP Test consisted of 65 selected response questions, seven constructed response questions, and no performance event questions. The seventh grade mathematics MAP Test consisted of 65 selected response questions, seven constructed response questions, and no performance event questions. The eighth grade mathematics MAP Test consisted of 65 selected response questions, nine constructed response questions, and one performance event question. All questions were aligned to the state grade level expectations in mathematics (Missouri Department of Elementary and Secondary Education, 2005a).

A MAP scale score for communications arts and mathematics was determined by the number of correct responses and points a student earned. The scale scores ranged from 450 to 910 . A score was only derived if a student completed all sessions of the MAP Test. For the sixth grade communication arts, test below basic was defined as a score from 505 to 630 , basic was defined as a score from 631 to 675 , proficient was defined as score from 676 to 703 , and advanced was defined as a score from 704 to 855 . For the seventh grade communication arts test, below basic was defined as a score from 515 to 633, basic was defined as a score from 634 to 679 , proficient was defined as a score from 680 to 711 , and advanced was defined as a score from 712 to 865 . For the eighth grade communication arts test, below basic was defined as a score from 530 to 638, basic was defined as a score from 639 to 695 , proficient was defined as a score from 696 to 722 , and advanced was defined as a score from 723 to 875 (Missouri Department of Elementary and Secondary Education, 2006a). 
For the sixth grade mathematics test, below basic was defined as a score from 495 to 627 , basic was defined as a score from 628 to 680 , proficient was defined as a score from 681 to 720 , and advanced was defined as a score from 721 to 845 . For the seventh grade mathematics test, below basic was defined as a score from 510 to 639 , basic was defined as a score from 640 to 684 , proficient was defined as a score from 685 to 723 , and advanced was defined as a score from 724 to 860 . For the eighth grade mathematics test, below basic was defined as a score from 525 to 669 , basic was defined as a score from 670 to 709 , proficient was defined as a score form 710 to 740 , and advanced was defined as a score from 785 to 910 (Missouri Department of Elementary and Secondary Education, 2006a).

The MAP Test was designed by the Missouri Department of Elementary and Secondary Education (DESE) in conjunction with CTB-McGraw Hill. The test aligned the assessments to the grade level expectations for each content area that were published by DESE. Questions were first written by content teachers and experts. Then they were reviewed by Missouri educators to make certain the item were aligned to the content strand and grade level expectations specified. Finally, the items were piloted and scored by educators to ensure questions were clear and measured what was intended (Missouri Department of Elementary and Secondary Education, n.d.).

The Missouri Department of Elementary and Secondary Education in conjunction with CTB-McGraw Hill also examined how student performance on items of a certain content strand compared to items assessing the same content strand. This was done to determine if the questions were assessing what they were intended to assess. From 1997 to 2000, all questions on the communication arts and mathematics MAP Test had a 
reliability score between .913 to .940 suggesting a high degree of reliability (Missouri Department of Elementary and Secondary Education, 2005b).

\section{Interview Protocol}

Participants from three sites in the district were selected to take part in a focus group or fill out a questionnaire. Using a multiple-category design (Krueger \& Casey, 2000), a focus group interview took place at one site, an interview took place at another site, and two questionnaires were filled out by students at the third site. The focus group was composed of four students. The participants were students currently enrolled in an academic recovery class or had been enrolled in an academic recovery class the previous year. The participant's guardians signed a written consent form (Appendix A) to participate in the focus group, and the students were given a youth consent form (Appendix B; Fink, 2006; Seidman, 2006).

The participants selected were contacted by mail to determine a convenient time for the focus group or interview. During the spring of 2008, the focus group interview and the interview were conducted in person and were audio recorded. The interviews were transcribed by the researcher. The transcripts were reviewed by the researcher and a third party to check for accuracy (Seidman, 2006). Fieldnotes of the focus group were gathered by the researcher to help aid understanding of the study (Emerson, Fretz, \& Shaw, 1995). The questionnaires were completed in the spring of 2008 and transcribed by the researcher. The transcripts were reviewed by the researcher and checked by a third party (Seidman).

The interview protocol (Appendix C) was developed with the intent of determining student perceptions and experiences with the academic recovery program. 
Open-ended questions were formulated to allow participants to describe their experiences with the academic recovery program and their changes in thinking associated with school. The questions were designed to ensure the research questions were addressed and to help determine if the academic recovery classes changed student perceptions of school (Merriam, 1998; Seidman, 2006).

The tapes of the focus group interview, the interview, the transcriptions of the interviews, the researcher's fieldnotes, related documents obtained for analysis, and the student MAP scores were kept in a secure location during the research (Fink, 2006). After the study was completed, all of the aforementioned data was destroyed.

\section{Data Analysis}

The data collected for this study was twofold. Part of the data was collected using quantitative techniques, and the other part of the data was collected using qualitative techniques. Each is described in the following paragraphs.

\section{Quantitative Analysis}

Research questions one, two, three and four were addressed by using quantitative methods. Both used MAP Test results and the classification of students in academic recovery classes.

Research Questions One and Two. To determine the effect of academic recovery classes on state assessments as measured by the MAP Test in communication arts and mathematics of students enrolled in academic recovery classes a Pearson's chi-square test of independence (Field, 2005) was used using the statistical software package SPSS and an online chi-square calculator (Physics, 2008). The categorical data of achievement level 
placements of advanced, proficient, basic, and below basic were used and were compared before and after the academic recovery class.

To determine if there was a relationship, an alpha level of .05 was used for analysis. If the alpha level was less than .05 , the differences in patterns of scores were considered to be statistically significant (Field, 2005). Hence, the program and achievement level placements would be considered to be related and dependent on each other.

Research Questions Three and Four. To compare the gain in scores for academic recovery students to similar students, a gain score for each student was calculated using the statistical software package SPSS. The gain scores were calculated for each student in communication arts and mathematics. To compare student scores in an academic recovery class to similar students, an independent samples $t$-test (Field, 2005) was used, using the statistical software package SPSS. The independent variable was the students' placement. The students fell into two categories: students in academic recovery classes or students not enrolled in academic recovery classes but qualified for the classes. The dependent variables were the MAP scores in communication arts and mathematics. The effect size of the intervention was calculated from the $t$-test.

To determine if the student scores were significantly different, an alpha level of .05 was used for the analysis. If the alpha level was less than .05 , the differences in scores were considered to be statistically significant (Field, 2005). Hence, the program would be found to be successful.

Additionally, to compare student scores in an academic recovery test on the MAP test to similar students on the MAP, test a chi-square analysis (Field, 2005) was used. The 
categorical data of achievement level placements of advanced, proficient, basic, and below basic were used and were compared between students in an academic recovery class to similar students.

To determine if there was a relationship, an alpha level of .05 was used for analysis. If the alpha level was less than .05 , the differences in patterns of scores were considered to be statistically significant (Field, 2005). Hence, the program and achievement level placements would be considered to be related and dependent on each other.

The overall national percent rank scores and the raw scores for each content area were used as the basis for comparison in the study. These scores were compared from year to year with a paired samples $t$-test (Field, 2005). A score for each strand in communication arts and mathematics was reported, but since the percent of questions in each strand varied from year to year, these scores were not used. Chi-square tests were used to compare the achievement level placements from year to year for students in academic recovery class and to compare students in academic recovery classes to similar students, since it was categorical data (Field, 2005).

Qualitative Analysis

Research question five was addressed by using qualitative research methods. Research has shown successful academic recovery programs help students improve their confidence and change how they think of learning (Ezarik, 2003). Qualitative research best allowed the researcher to determine student's perceptions and experiences associated with the program and determine if the classes resulted in a positive change in thinking 
about education for the participants involved. It allowed for an exploration of these issues (Merriam, 1998).

One focus group with four students was conducted, one interview was conducted, and two questionnaires were completed. The interviews and questionnaires were transcribed verbatim leading to a transcript that was used for analysis (Krueger \& Casey, 2000: Seidman, 2006). Fieldnotes were also rewritten and narratives were developed and transcribed (Emerson, Fretz, \& Shaw, 1995). An evolving, open coding strategy was used to identify categories and sort interview transcripts, fieldnotes, and documents (Merriam, 1998). The research questions were used as the initial categories for coding. Subcategories were identified as themes in the data emerged. Coding continued until no new categories and themes were found and the data themes became redundant (Merriam, 1998).

The researcher did several things to ensure the trustworthiness of the qualitative piece. Triangulation of the data was achieved by confirming findings of the focus group and interview transcripts with field notes (Merriam, 1998). Field notes were comprised of jottings the researcher took before, during, and after the focus group interviews. The researcher later developed narratives from the field notes to aid in understanding (Emerson, Fretz, \& Shaw, 1995). The interview and questionnaire findings were reviewed by a third party (Seidman, 2006; Merriam). Additionally, the researcher clarified any biases about the academic recovery program and the study before beginning collection of the data to ensure the study was not influenced by them. An audit trail was left so others could replicate the study (Merriam, 1998). 


\section{Summary}

The research questions, hypotheses, and the research design were addressed and discussed in chapter three. The study was a mixed design study consisting of a quantitative piece and a qualitative piece. The quantitative part of the study addressed the effect of an academic recovery program on student test scores. It allowed for the comparison of students in academic recovery classes to similar students that qualified for academic recovery classes but were not enrolled in them (Field, 2005). Students test scores in communication arts and mathematics on the state achievement test, the MAP, were used as the measure of study. The population of participants consisted of middle school students enrolled in academic recovery classes and students comparable to these students experiencing a traditional middle school education. The qualitative part of the study addressed the perceptions and experiences of the participants in the academic recovery program. A focus group interview, an interview, questionnaires, fieldnotes, and related documents were used for data collection (Krueger \& Casey, 2000; Emerson, Fretz, \& Shaw, 1995). Participants were middle school students enrolled in academic recovery classes or had been previously enrolled in them.

The results of the quantitative piece and qualitative piece of this study are presented in detail in chapter four. Chapter five includes a summary of the study and presents the findings of the study. Additionally, chapter five addresses implications for practice in education and further recommendations for future studies. Appendices of the

consent form used for the participants and their guardians (Appendix A; Appendix B) and the interview protocol (Appendix C) are available for review following the reference list. 


\section{CHAPTER FOUR}

\section{RESULTS}

\section{Introduction}

The purpose of this study was to determine how effective an academic recovery program at the middle school level was in improving student academic achievement in communication arts and mathematics, using scores on the state assessment, the Missouri Assessment Program, as the measure of success. The study compared student test scores in communication arts and mathematics before and after the implementation of the program for students in academic recovery program classes to students that qualified for the classes but were not enrolled in them. Additionally, the purpose of this study was to determine what the student's perceptions about their experiences were associated with the academic recovery program and to determine if the program resulted in a positive change of thinking about school for the students (Owings \& Kaplan, 2001). This was defined by an improved outlook of school and life that was evidenced in a focus group interview, an interview, and questionnaires. This study was proposed as a possible tool for the school district officials to use when evaluating the middle school academic recovery program (Patton, 1997).

The purpose of chapter four is to present the research findings. The research questions and hypothesis are first revisited. Then the findings for the quantitative research questions are presented followed by the discussion of the findings for the qualitative research questions. A summary of the chapter follows.

\section{Research Questions}

Within the context of the study, the following research questions were addressed: 
1. What was the effect of academic recovery classes on the state assessment, as measured by the Missouri Assessment Program (MAP) Test in communication arts, on middle school students (grades 6, 7, and 8) enrolled in academic recovery classes?

2. What was the effect of academic recovery classes on the state assessment, as measured by the MAP Test in mathematics, on middle school students (grades 6, 7, and 8) enrolled in academic recovery classes?

3. What was the comparison of middle school student test scores, as measured by the communication arts component of the MAP Test, of middle school students (grades 6, 7, and 8) in academic recovery classes and students qualified for academic recovery classes but not enrolled in academic recovery classes?

4. What was the comparison of middle school student test scores, as measured by the mathematics component of the MAP Test, of middle school students (grades 6,7 , and 8 ) in academic recovery classes and students qualified for academic recovery classes but not enrolled in academic recovery classes?

5. What were the perceptions of middle school student's (grades 6, 7, and 8) experiences in academic recovery classes?

\section{Research Hypotheses}

The following research hypotheses were examined:

Hypothesis 1: Student test scores in communication arts as measured on the MAP improved (alpha level .05) for students in academic recovery classes.

Hypothesis 2: Student test scores in mathematics as measured on the MAP 
improved (alpha level .05) for students in academic recovery classes.

Hypothesis 3: Students in academic recovery classes had greater increases in communication arts test scores (alpha level .05) as measured by the MAP than students who qualified for academic recovery classes but were not enrolled in the classes.

Hypothesis 4: Students in academic recovery classes had greater increases in mathematics test scores (alpha level .05) as measured by the MAP than students who qualified for academic recovery classes but were not enrolled in the classes.

\section{Quantitative Analysis}

Research questions one, two, three, and four were addressed using quantitative research methods. All four research questions were analyzed using the statistical software package SPSS. Additionally, research questions one and two were analyzed with an online chi-square calculator (Physics, 2008). The Missouri Assessment Program (MAP) Test results for the 2005-2006 school year and the 2006-2007 school year were used. The following sections detail the results of the analysis for research questions one, two, three, and four.

Research Question One

To determine the effect of academic recovery classes on the state assessment, the MAP, in communication arts of students enrolled in academic recovery classes, a Pearson's chi-square test of independence (Field, 2005) was used using the statistical software Package SPSS version 14.0 and an online chi-Square calculator (Physics, 2008). The categorical data of achievement level placements of advanced, proficient, basic, and below basic were used and were compared before and after the intervention. Table 4 
illustrates the number of students testing into advanced, proficient, basic, and below basic categories on the communication arts component of the MAP for students in academic recovery classes for the 2005-2006 school year and the 2006-2007 school year.

Table 4

Academic Recovery Students' Categorical Placements for the Communication Arts Section of the MAP Test

\begin{tabular}{ccccc}
\hline School Year & Below Basic & Basic & Proficient & Advanced \\
$2005-2006$ & 7 & 12 & 2 & 0 \\
$2006-2007$ & 4 & 14 & 3 & 0 \\
\hline
\end{tabular}

A chi-square test of independence was calculated comparing the frequency of occurrence of academic recovery students testing in below basic, basic, proficient, and advanced on the MAP Test for communication arts. The proficient and advanced cells were collapsed for the analysis. The data for the 2005-2006 school year and the 20062007 school year were used for the analysis. It was hypothesized students in academic recovery classes would improve on their MAP communication arts test. A significant relationship was not found (chi-square $(2)=1.17, p=.557$ ). Students in academic recovery classes were not more likely to be in below basic, basic, proficient, or advanced categories on the communication arts component of the MAP test from the 2005-2006 school year to the 2006-2007 school year. 


\section{Research Question Two}

To determine the effect of academic recovery classes on the state assessment, the MAP, in mathematics of students enrolled in academic recovery classes a Pearson's chisquare test of independence (Field, 2005) was used using the statistical software package SPSS and an online chi-square calculator (Physics, 2008). The categorical data of achievement level placements of advanced, proficient, basic, and below basic were used and were compared before and after the intervention. Table 5 illustrates the number of students testing into advanced, proficient, basic, and below basic categories for students in academic recovery class on the mathematics component of the MAP Test for the 20052006 school year and the 2006-2007 school year.

A chi-square test of independence was calculated comparing the frequency of occurrence of students testing in below basic, basic, proficient, and advanced on the MAP Test in mathematics for students in academic recovery classes for the 2005-2006 school year and the 2006-2007 school year. The proficient and advanced cells were collapsed for the analysis. It was hypothesized students in academic recovery classes would improve on their MAP Mathematics Test. A significant relationship was not found (chi-square (2) $=1.17, p=.943)$. Students in academic recovery classes were not more likely to be in below basic, basic, proficient, or advanced categories on the mathematics component of the MAP test from the 2005-2006 school year to the 2006-2007 school year. 
Table 5

Academic Recovery Students' Categorical Placements for the Mathematics Section of the MAP Test

\begin{tabular}{ccccc}
\hline School Year & Below Basic & Basic & Proficient & Advanced \\
$2005-2006$ & 7 & 12 & 2 & 0 \\
$2006-2007$ & 6 & 13 & 2 & 0 \\
\hline
\end{tabular}

\section{Research Question Three}

Gain scores. To compare MAP communication arts scores of students in academic recovery classes and a similar group of students not in academic recovery classes, a gain score was first calculated for each student. This was done by taking the difference of the communication arts numerical MAP score for 2006-2007 and the communication arts numerical score for 2005-2006 for each student. This statistical software package SPSS was used to calculate the gain for each student. The results of the gain scores for the communication arts MAP section for students in academic recovery classes compared to a similar group of students not in academic recovery classes are presented in Table 6.

The students in academic recovery classes gained a higher average of points on the communication arts component of the MAP than a similar group of students who were not in academic recovery classes. On average the students in academic recovery classes gained six more points than their peers. 
Table 6

Comparison of Gain Scores on the Communication Arts Component of the MAP from 2005-2006 to 2006-2007

\begin{tabular}{lcccc}
\hline & $\begin{array}{c}\text { Number of } \\
\text { Students }\end{array}$ & Mean & Standard & Standard Error \\
& & & Deviation & of the Mean \\
\hline AR Students & 21 & 12.4762 & 27.66517 & 6.03704 \\
Non AR Students & 31 & 6.4516 & 15.39879 & 2.76570 \\
\hline
\end{tabular}

Note. $\mathrm{AR}=$ Scores of students in academic recovery classes. Non $\mathrm{AR}=$ Scores of students not in academic recovery classes.

Independent samples t-tests. To compare the gain scores of students in academic recovery classes to similar students, an independent samples $t$-test was used, using the statistical software package SPSS (Field, 2005). The independent variable was the students' placement. The students fell into two categories: students in academic recovery classes or students not enrolled in academic recovery classes but qualified for the classes. The dependent variables were the numerical MAP scores in communication arts. There was not a significant difference in the gain scores between the two groups of students (Students in academic recovery classes mean $=12.4792, \mathrm{sd}=27.66517$; students not in academic recovery classes mean $=6.4516, \mathrm{sd}=15.39879 ; t(50)=1.007, p=.319)$. The gain scores for students in academic recovery classes were not statistically different than the gain scores for students not in academic recovery classes on the communication arts MAP test. An effect size was calculated for the group and found to be $r=.141$ which is considered a small effect (Field, 2005). 
Another independent samples $t$-test was run using SPSS to determine if the two groups were similar before the intervention, academic recovery classes, and after the intervention. The mean scores for both groups' communication arts MAP scores were compared before and after the intervention. Table 7 details the mean and standard deviation for both groups of students.

Table 7

Comparison of Means for the Communication Arts Component of the MAP

\begin{tabular}{|l|l|c|c|c|c|}
\hline School Year & & $\begin{array}{c}\text { Number of } \\
\text { Students }\end{array}$ & Mean & Standard & Standard Error of the \\
& & 21 & 646.05 & 25.433 & Mean \\
\hline $2005-2006$ & AR & 31 & 661.16 & 23.351 & 5.550 \\
\hline $2005-2006$ & Non AR & 21 & 658.52 & 30.854 & 4.194 \\
$2006-2008$ & AR & 31 & 667.61 & 25.489 & 6.733 \\
\hline
\end{tabular}

Note. $\mathrm{AR}=$ Students in academic recovery classes. Non $\mathrm{AR}=$ Students not in academic recovery classes

An independent samples $t$-test indicated students in academic recovery classes were significantly behind based on the communication arts MAP scores for the 20052006 school year $(t(50)=-2.209, p=.032)$. However, they were not significantly behind after the academic recovery classes intervention, as indicated by the 2006-2007 Communication Arts MAP scores $(t(50)=-1.158, p=.252)$. After a year in academic recovery classes, student test scores on the communication arts section of the MAP were 
no longer statistically different than a similar group of their peers who were not in academic recovery classes.

Chi-square tests. To determine if there was a categorical difference between students in academic recovery classes and the comparison group on the communication arts component of the MAP test before and after the intervention, two chi-square tests of independence (Field, 2005) were run using an online chi-square calculator (Physics, 2008). The categorical data of achievement level placements of advanced, proficient, basic, and below basic were used and were compared before and after the intervention. Table 8 illustrates the number of students testing into the advanced, proficient, basic, and below basic categories for students in academic recovery class and the comparison group on the communication arts component of the MAP test for the 2005-2006 school year and the 2006-2007 school year.

A chi-square test of independence was calculated comparing the frequency of occurrence of students testing in below basic, basic, proficient, and advanced on the MAP test in communication arts of students in academic recovery classes to the comparison group for the 2005-2006 school year. The proficient and advanced cells were collapsed for the analysis. A significant relationship was found (chi-square (2) $=8.07, p=.018$ ). Students in academic recovery classes were more likely to be in below basic, basic, proficient, or advanced categories on the communication arts component of the MAP test than a similar group of students for the 2005-2006 school year.

A chi-square test of independence was calculated comparing the frequency of occurrence of students testing in below basic, basic, proficient, and advanced on the MAP Test in communication arts of students in academic recovery classes to the comparison 
group for the 2006-2007 school year. A significant relationship was not found (chi-square $(3)=2.22, p=.528)$. Students in academic recovery classes were not more likely to be in below basic, basic, proficient, or advanced categories on the communication arts component of the MAP test than a similar group of students for the 2006-2007 school year. Based on the chi-square analyses, academic recovery student's categorical placements were statistically different on the communication arts section of the MAP Test before the intervention. However, after one year of the intervention, the academic recovery student's communication arts categorical placements were no longer statistically different than the comparison group.

Table 8

Comparison of Categorical Placements on the Communication Arts Component of the $M A P$

\begin{tabular}{|l|c|c|c|c|c|}
\hline Placement & School Year & Below Basic & Basic & Proficient & Advanced \\
\hline AR & $2005-2006$ & 7 & 12 & 2 & 0 \\
\hline Non AR & $2005-2006$ & 2 & 19 & 10 & 0 \\
\hline AR & $2006-2007$ & 4 & 14 & 3 & 0 \\
\hline Non AR & $2006-2007$ & 3 & 22 & 4 & 2 \\
\hline
\end{tabular}

Note. $\mathrm{AR}=$ Students in academic recovery. Non $\mathrm{AR}=$ Comparison group of students not in academic recovery.

\section{Research Question Four}

Gain scores. To compare MAP mathematics scores of students in academic recovery classes and a similar group of students, a gain score was first calculated for each 
student. This was done by taking the difference of the mathematics numerical MAP score for 2006-2007 and the mathematics numerical score for 2005-2006 for each student. This statistical software package SPSS was used to calculate the gain for each student. The results of the gain scores for the mathematics section of the MAP for students in academic recovery classes compared to students not in academic recovery classes are presented in Table 9.

The students in academic recovery classes gained a slightly higher average of points on the mathematics component of the MAP than a similar group of students that were not in academic recovery classes. On average the students in academic recovery classes gained two more points than their peers.

Table 9

Comparison of Gain Scores on the Mathematics Component of the MAP from 2005-2006 to $2006-2007$

\begin{tabular}{lcccc}
\hline & $\begin{array}{c}\text { Number of } \\
\text { Students }\end{array}$ & Mean & Standard & Standard Error \\
& & & Deviation & of the Mean \\
\hline AR Students & 21 & 12.2857 & 31.69407 & 6.91621 \\
Non AR Students & 31 & 10.1613 & 19.79242 & 3.55482 \\
\hline
\end{tabular}

Note. $\mathrm{AR}=$ Scores of students in academic recovery classes. Non $\mathrm{AR}=$ Scores of students not in academic recovery classes.

Independent samples t-tests. To compare the gain scores of students in academic recovery classes to similar students, an independent samples $t$-test was used, using the statistical software package SPSS (Field, 2005). The independent variable was the 
students' placement. The students fell into two categories: students in academic recovery classes or students not enrolled in academic recovery classes but qualified for the classes. The dependent variables were the numerical MAP scores in mathematics. There was not a significant difference in the gain scores between the two groups of students (students in academic recovery classes mean $=12.2857, \mathrm{sd}=31.69407$; students not in academic recovery classes mean $=10.1613, \mathrm{sd}=19.79242 ; t(50)=.298, p=.767)$. The gain scores for students in academic recovery classes were not statistically different than the gain scores for students not in academic recovery classes on the Mathematics MAP Test. An effect size was calculated for the group and found to be $r=.042$ which is considered to have no effect (Field).

Another independent samples $t$-test, using SPSS was used, to determine if the two groups were similar before the intervention, academic recovery classes, and after the intervention. The mean scores for both groups' mathematics MAP scores were compared before and after the intervention. Table 10 details the mean and standard deviation for both groups of students.

An independent samples $t$-test indicated students in academic recovery classes were significantly behind based on the mathematics MAP scores for the 2005-2006 school year $(t(50)=-2.256, p=.028)$. However, they were not significantly behind after the academic recovery classes intervention, as indicated by the 2006-2007 mathematics MAP scores $(t(50)=-1.595, p=.117)$. After a year in academic recovery classes, student test scores on the mathematics section of the MAP were no longer statistically different than a similar group of their peers who were not in academic recovery classes. 
Table 10

Comparison of Means for the Mathematics Component of the MAP

\begin{tabular}{|c|c|c|c|c|c|}
\hline School Year & & $\begin{array}{c}\text { Number of } \\
\text { Students }\end{array}$ & Mean & $\begin{array}{l}\text { Standard } \\
\text { Deviation }\end{array}$ & $\begin{array}{c}\text { Standard Error of the } \\
\text { Mean }\end{array}$ \\
\hline $2005-2006$ & $\overline{\mathrm{AR}}$ & 21 & 643.00 & 28.562 & 6.233 \\
\hline $2005-2006$ & Non AR & 31 & 658.94 & 22.295 & 4.004 \\
\hline $2006-2007$ & $\overline{\mathrm{AR}}$ & 21 & 655.59 & 34.245 & 7.473 \\
\hline 2006-2007 & Non AR & 31 & 669.10 & 27.980 & 5.025 \\
\hline
\end{tabular}

Note. $\mathrm{AR}=$ Students in academic recovery classes. Non $\mathrm{AR}=$ Students not in academic recovery classes.

Chi-square tests. To determine if there was a categorical difference between students in academic recovery classes and the comparison group on the mathematics component of the MAP test before and after the intervention, two chi-square tests of independence (Field, 2005) were run using an online chi-square calculator (Physics, 2008). The categorical data of achievement level placements of advanced, proficient, basic, and below basic were used and were compared before and after the intervention. Table 11 illustrates the number of students testing into the advanced, proficient, basic, and below basic categories for students in academic recovery class and the comparison group on the mathematics component of the MAP Test for the 2005-2006 school year and the 2006-2007 school year. 
Table 11

Comparison of Categorical Placements on the Mathematics Component of the MAP

\begin{tabular}{|l|c|c|c|c|c|}
\hline Placement & School Year & Below Basic & Basic & Proficient & Advanced \\
\hline AR & $2005-2006$ & 7 & 12 & 2 & 0 \\
\hline Non AR & $2005-2006$ & 0 & 25 & 6 & 0 \\
\hline AR & $2006-2007$ & 6 & 13 & 2 & 0 \\
\hline Non AR & $2006-2007$ & 5 & 21 & 4 & 1 \\
\hline
\end{tabular}

Note. $\mathrm{AR}=$ Students in academic recovery. Non $\mathrm{AR}=$ Comparison group of students not in academic recovery.

A chi-square test of independence was calculated comparing the frequency of occurrence of students testing in below basic, basic, proficient, and advanced on the MAP Test in mathematics of students in academic recovery classes to the comparison group for the 2005-2006 school year. The proficient and advanced cells were collapsed for the analysis. A significant relationship was found (chi-square $(2)=12.1, p=.002$ ). Students in academic recovery classes were more likely to be in below basic, basic, proficient, or advanced categories on the mathematics component of the MAP test than a similar group of students for the 2005-2006 school year.

A chi-square test of independence was calculated comparing the frequency of occurrence of students testing in below basic, basic, proficient, and advanced on the MAP Test in mathematics of students in academic recovery classes to the comparison group for the 2006-2007 school year. A significant relationship was not found (chi-square (3)= $.645, p=.886)$. Students in academic recovery classes were not more likely to be in below basic, basic, proficient, or advanced categories on the mathematics component of 
the MAP Test than a similar group of students for the 2006-2007 school year. Based on the chi-square analyses, academic recovery students' categorical placements on the mathematics section of the MAP Test were statistically different before the intervention. However, after one year of the intervention, academic recovery student's categorical placements in mathematics were no longer statistically different than the comparison group.

Summary

Research questions one, two, three, and four composed the quantitative part of the research study. All four questions were analyzed using the statistical software package SPSS and an online chi-square calculator (Physics, 2008). Hypotheses one and two were not supported as it was found students in academic recovery classes did not statistically improve on the MAP Test in the communication arts and mathematics, as they were not more likely to test into basic, below basic, proficient, or advanced categories on the state test from 2006-2006 to 2006-2007 in both subjects. Hypotheses three and four were also not supported. Students in academic recovery classes did not statistically improve more than a group of student that qualified for academic recovery classes but were not enrolled in the classes in communication arts or mathematics. However, students in academic recovery classes did have slightly larger gains in their improvement than the group of similar students not enrolled in academic recovery classes on both the communication arts and mathematics section of the MAP test. Furthermore, students in academic recovery classes test scores were significantly behind the comparison group before the intervention in both communication arts and mathematics but were not significantly behind the comparison group after the intervention in both communication arts and 
mathematics. Additionally, students in academic recovery classes' categorical placements were statistically different than the comparison group before the intervention in communication arts and mathematics, but their categorical placements were not statistically different than the comparison group after the intervention in communication arts and mathematics.

\section{Qualitative Analysis}

Research question five, what are the perceptions of middle school student's experiences in academic recovery classes, was analyzed using qualitative analysis. One focus group was conducted with four academic recovery students, one interview was conducted with an academic recovery student, and two questionnaires were filled out by students in academic recovery classes. The questionnaires were composed of the same questions used in the interviews. Each interview and questionnaire were transcribed verbatim, and analyzed for emergent themes. Three emergent themes arose from the data, connections to school, obstacles at school, and future planning; each theme was then divided into sub-themes. Figure 1 details the break down of the data and the emergent themes.

\section{Connections to School}

Through the analysis of interview and questionnaire transcripts, the degree of connection the academic recovery students felt at school was a dominating theme that emerged. Through further analysis there were four subthemes that emerged from the data. They are as follows: preference for hands-on learning, academic recovery student's comfort in academic recovery classes, friendships students developed in academic 
recovery classes and academic recovery student's positive relationship with their academic recovery teacher. Each sub-theme is explored in the following paragraphs.

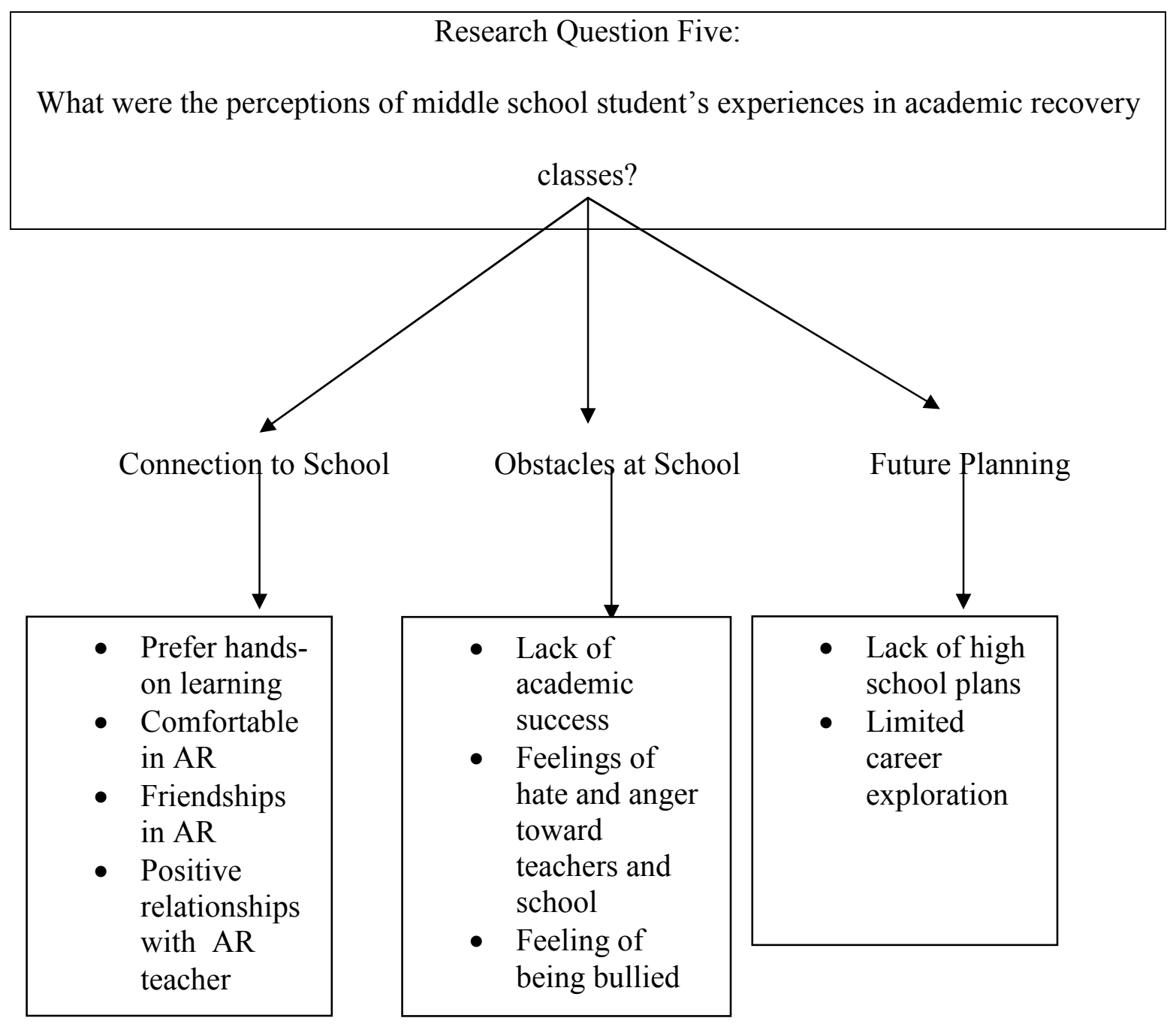

Figure 1. Outline of Qualitative Themes and Related Sub-Themes

Prefer hands-on learning. The academic recovery students had some interests at school, but they were generic interests in that they were general interests and the students did not know why they liked the things they did. When asked what learning excited them, two students stated technology and two students stated gym. When asked why they liked 
these classes, one student responded by saying "because of the games and you get to run around," and another student stated "they are fun, you get to do fun stuff, like, I got to make a handbag, and I got to make snacks." The same types of responses were given when the students were asked about what they liked about their classes. Almost all of the respondents stated they liked it when they got to do fun stuff in their classes like play games. The student's interests at school were vague and centered around games, making things, and fun.

Comfortable in academic recovery. The academic recovery classes are set up so that students are with the same cohort of students and the same teacher in a small class setting. All of the students questioned wanted to have academic recovery classes again next year. When asked why, one student stated "because these are my weakest classes." One student mentioned she felt more comfortable sharing her work with the class since it was the same group. Another student stated he "interacted differently in those classes (academic recovery classes) than other classes." However, many of the students noted they still thought their academic recovery classes were boring. One student stated she was "not really" ever excited about going to communication arts, math, science, or social studies, which were her academic recovery classes. Students thought their academic recovery classes were boring and they were not excited about going to them, which is consistent with the limited academic interests they expressed.

Friendships in academic recovery. Friendships are an important factor in the amount of connectedness students feel to school. All of the students, except one, felt they had formed friendships in their academic recovery classes. The student's responses illustrated their friendships. One student stated he considered the friends he made in these 
classes "close enough to be brothers." Another stated she felt the "students in AR (academic recovery) were always there to help you." The one student who felt she had not formed any friendships stated she only hung out with the students in academic recovery classes during class time; she stated she really did not hang out with anyone at school, and sometimes felt she was bullied by students in her academic recovery classes. Overall, most of the students felt they had made new friendships in their academic recovery classes and were comfortable being themselves with this group of peers.

Positive relationships with academic recovery teacher. All of the students interviewed felt a positive relationship with their academic recovery teacher. When students were asked what their relationship was like with their teacher, a variety of positive answers were given. Some of the responses included "I like my teacher, she's pretty cool;" "I like my teacher and I think she respects me;" and "she's (the teacher) is really nice and she cares about all the kids."

Some of the students interviewed had academic recovery classes the year prior but were not currently enrolled in them because the classes had been cut when the principal was required to reduce the number of staff in the building. Through their responses it was apparent they had a formed a connection with the academic recovery teacher who they had not been able to replace when they were back in regular classes. The students felt their current teachers did not respect them the way their academic recovery teacher did. When asked why, a student stated "teachers (their current teachers) just like to yell at you" and their former teacher "talked to us about our mistakes." Another stated he felt his current teachers "just want us to sit down." The students acknowledged none of their current teachers had asked them what they like to do, and they did not have a relationship 
with their current teachers like they had had with their academic recovery teacher. They felt their academic recovery teacher was a great teacher who helped them, but now they were feeling isolated and alone at school.

\section{Obstacles at School}

Connections have started to form for students in academic recovery classes; however, there are still some obstacles that face these students and are hindering their performance at school. Through analysis of the data, three sub-themes emerged as obstacles that were hindering the students' progress at school. Two of the sub-themes were teacher related: lack of academic success and the feelings of hate and anger the students have towards their teachers and school. The third sub theme is the anger academic recovery students feel when other students are picking on them. The following paragraphs explore the obstacles at school academic recovery students are facing.

Lack of academic success. All students felt their academic recovery teacher cared for them, but they all still felt they were unsuccessful in the classroom and were frustrated with their grades as evidenced by one student's response about what frustrated him. He replied he was frustrated "with always getting $0 \%$ or low grades when I complete an assignment I tried hard on." He wished his teachers would grade more on completion and effort. Another student responded by saying it was frustrating that her grades where still so low, yet she has worked so hard. When asked how their grades were this year, many students admitted their grades were still low, and some felt they were only successful when their teachers helped them. Academically, the academic recovery students were still not excelling. This is return, was exacerbating a lot of feelings of 
frustration when they tried on assignment but were receiving the same grades they were when they were not trying.

Feelings of hate and anger towards teachers and school. The lack of student success was making the students frustrated, and students were having feelings of hate and anger towards teachers and school in general. These feelings of hate and anger seem to stem from the fact they were not achieving at school, and the students perceived this as their teacher's fault. When the students were asked what makes them feel angry at school, the majority of the responses were related to their teachers. One student stated she was angry "sometimes when the teacher doesn't help me." Another student iterated "she hates science because it is hard and confusing." A couple of other students declared they hated the pressure they feel at school to do well; with another student saying he hated the fact he was forced to come to school every day. Many of the complaints the students had about their teachers had to do with the fact they were not doing well at school, and this was translating as a perceived lack of caring by the teachers. The thought of the students seemed to be, I am not doing well at school because the teachers do not care for me; if they did, I would be successful.

Feelings of being bullied. While many of the students in academic recovery classes had formed friendships in their classes, there were still some instances of when they felt like an outsider. A couple of the students admitted they felt angry when students picked on them at school. One student stated she hated it when "kids making fun of me." The other stated he felt bullied when kids told him he was a reject and the class was better without him. These incidents of bullying made the students feel angry at school, but these incidents did not happen in their academic recovery classes. 


\section{Future Planning}

One of the most concerning findings the data reveled was the lack of future planning the students in academic recovery classes have done. The students interviewed did not seem to have any idea of what classes they were going to take in high school and what career path they would like to take. The following sections delineate the student data into two sections: lack of high school plans and limited career exploration.

Lack of high school plans. The majority of the students interviewed will be going into high school next year and beginning the final four years of their public school education. This is a time for students to take classes in the areas that interest them and participate in sports and clubs. At the high school level there is a multitude of extracurricular activities in which students can participate. Additionally, all of the students will be attending large high schools that offer a wide variety of classes. The majority of respondents declared they were interested in taking PE and choir. One student did mention he was interested in taking a welding class. Many of the respondents were unsure as to what classes they were taking next year. One student demonstrated this by stating "I don't know what I am taking next year, my mom filled it out." She was unaware of what classes she was taking and what choices she had in the classes she could take. All the students were interested in participating in a club or sport. Responses varied and are as follows: art club, football, tennis, color guard, and drama.

Many of the students had concerns about high school. All were worried about their grades as they were not currently seeing any success in the classroom. "I am worried about failing ninth grade" was stated by one individual. Other students responded "I am worried about getting around" in the school and "I just want to survive." Finally, one 
student claimed she was scared of "the kids" in high school. The lack of high school planning for the academic recovery students is related to their lack of career exploration.

Limited career exploration. Students were asked what their future plans were and what careers they were considering. Many of the students stated they wanted to go to college but had no idea what for. Additionally, as previously mentioned, the students had no idea what classes to take in high school so they could go to college. One student illustrated this by saying her plans were to "go to college, go to" community college "to become an OBGYN." She was certain community college was where she would to go to become a doctor; however, she did not know what classes she was taking next year. The academic recovery students interviewed were confused about their future. The students had no clue as to what classes they would take in high school and, and were unclear about future career possibilities and the schooling needed for different careers.

\section{Summary}

Research question five was analyzed using qualitative analysis. One focus group was conducted with academic recovery students, one interview was conducted with an academic recovery student, and two questionnaires were filled out by academic recovery students. The questionnaires consisted of the same questions asked in the interviews. Three themes emerged from the data as it was coded: connection to school, obstacles at school, and future planning. Each theme was then broken down into sub themes. Students felt they had a positive connection with their academic recovery teacher, had formed friendships at school, and had developed some interests at school. However, the students still were struggling academically at school and felt they were sometimes being bullied. They were angry at the teachers as they felt it was their fault they were failing. Many of 
the students were unclear as to what their future plans were; they had a vague idea what classes they would be taking next year and what careers they were interested in pursuing.

\section{Summary}

In chapter four, the analysis of the data was presented for the mixed study. Research questions one, two, three, and four were analyzed using quantitative analysis. All four of the corresponding hypotheses were not supported by the data. Students in academic recovery classes were not more likely to test into the advanced, proficient, below basic, or basic categories on the communication arts and mathematics test from 2005-2006 to 2006-2007. Students in academic recovery classes did not significantly gain more on the MAP Test in communication arts and mathematics than a similar group of their peers. However, the academic recovery students were significantly behind the comparison group of peers in 2005-2006 on the MAP Test in communication arts and mathematics but were not significantly behind their peers on the MAP Test in communication arts and mathematics in 2006-2007.

Research question five was analyzed using qualitative analysis. The data transcripts from a focus group interview with four academic recovery students, an interview with an academic recovery student, and two questionnaires filled out by students in academic recovery classes were analyzed. Three themes emerged from the data: connections to school, obstacles at school, and future planning. The analysis for each theme was presented with the related sub themes.

Chapter five presents a summary of the design of the study and findings. Then implications for future practice are presented followed by recommendations for future research. Appendices of the consent form for the guardians (Appendix A), the consent 
form for the students (Appendix B), and the interview protocol (Appendix C) are available for review following the reference list. 


\section{CHAPTER FIVE}

\section{DISCUSSION}

\section{Introduction}

With academic achievement and graduations rates of the United States public schools at the focal front of national attention, schools have been mandated to develop programs aimed at improving student achievement. Alternative interventions used to be a high school phenomenon, but interventions are taking place at an earlier stage in an atrisk student's life. Research has shown that alternative interventions that take place in elementary school and middle school may be more successful than high school interventions (Vaughn, Bos, \& Schumm, 2007) because these programs try to fix gaps in at-risk student achievement earlier. Successful intervention programs develop positive relationships and connections (Cornelius-White, 2007), implement peer tutoring (Edward, Mumford, Schillingford, \& Serra-Roldan, 2007), help students transition from one learning experience to the next (Ezarik, 2003), use a variety of teaching methods (Carpentier, 2007), provide additional support during the school day and outside the school day (Ezarik), and have policies aimed at eliminating retention (Ezarik).

The purpose of this study was to determine if a middle school program, entitled academic recovery, was helping improve student achievement in these classes. The program was designed to help struggling middle school students become successful in school before they entered high school. Five research questions were developed and analyzed using quantitative and qualitative methods. The results of these analyses were presented in chapter four. A discussion of these findings is presented in the following sections. First the design of the study and findings are summarized. Then, implications 
for practice and limitations are addressed. Finally, recommendations for future research are presented.

\section{Design of Study}

This study was designed to determine how successful a middle school academic recovery program was at improving student performance in communication arts and mathematics on the state achievement test, the Missouri Assessment Program (MAP). Additionally, the study aimed to determine what the perceptions of the academic recovery student's experiences were of their academic recovery classes. Five research questions were developed to evaluate this problem; four of the research questions were quantitative and one was qualitative. Patton's (1997) utilization-focused evaluation was used as the theoretical underpinning for the study. In addition to Patton's theory, the academic recovery program used several characteristics of effective alternative programs. The program provided extended learning opportunities and more support at school (Ezarik, 2003). It was also structured to provide small homogenous classes (SchweikerMarra \& Pula, 2005) with the same teacher to help build student connections (Edward et al., 2007).

Research questions one, two, three, and four were analyzed using quantitative methods. Research questions one and two were designed to determine what the effect of the academic recovery classes were on the student's placement on the communication arts and mathematics component of the MAP. Chi-square tests were run using the statistical software package SPSS (Field, 2005) and an on-line chi-square calculator (Physics, 2008). Research questions three and four were designed to determine what the comparison of scores on the communication arts and mathematics component of the 
MAP Test were between academic recovery students and students qualified for academic recovery but not enrolled in academic recovery classes. The gain in scores and effect sizes were calculated and several $t$-tests were run using the statistical software package SPSS (Field).

Research question five was addressed using qualitative methods. One focus group interview of four academic recovery students was conducted, one interview with an academic recovery student was conducted, and two questionnaires were filled out by academic recovery students. The questionnaires contained the same questions that were asked in the interviews (Appendix C). Parental consent was obtained prior to the interviews (Appendix A), and students were given a youth consent script outlining their rights (Appendix B). The interviews were audio recorded and fieldnotes were taken (Emerson, Fretz, \& Shaw, 1995). The interviews and questionnaires were transcribed verbatim and analyzed using an open evolving coding strategy (Seidman, 2006). Three themes and their related sub themes emerged from the data and were presented.

The problem studied in this research was the effect an alternative middle school intervention had on student performance and perceptions. Therefore, the research was designed to determine if these classes were helping at-risk middle school students improve their academic achievement and attitudes about school. Quantitative and qualitative methods were used to answer the research questions subsequently developed.

\section{Summary of Findings}

This was a mixed study that included quantitative and qualitative analyses. Research questions one, two, three, and four were evaluated using quantitative methods and research question five was analyzed using qualitative methods. The research 
questions are first presented for review, and then, the findings for each research questions are addressed.

\section{Research Questions}

Within the context of the study, the following research questions were addressed:

1. What was the effect of academic recovery classes on the state assessment, as measured by the Missouri Assessment Program (MAP) Test in communication arts, on middle school students (grades 6,7 and 8) enrolled in academic recovery classes?

2. What was the effect of academic recovery classes on the state assessment, as measured by the MAP Test in mathematics, on middle school students (grades 6, 7, and 8) enrolled in academic recovery classes?

3. What was the comparison of middle school student test scores, as measured by the communication arts component of the MAP Test, of middle school students (grades 6, 7, and 8) in academic recovery classes and students qualified for academic recovery classes but not enrolled in academic recovery classes?

4. What was the comparison of middle school student test scores, as measured by the mathematics component of the MAP Test, of middle school students (grades 6,7 , and 8 ) in academic recovery classes and students qualified for academic recovery classes but not enrolled in academic recovery classes?

5. What were the perceptions of middle school student's (grades 6, 7 and 8) experiences in academic recovery classes? 


\section{Research Question One - Effect on Communication Arts Scores}

The results of the statistical analysis found academic recovery students were not more likely to be in the below basic, basic, proficient, or advanced categories on the communication arts component of the MAP test from the 2005-2006 school year to the 2006-2007 school year. Hypothesis one was not supported. The results were statistically the same from one school year to the next. There was a slightly lower number of academic recovery students in the below basic category of the communication arts section of the MAP after the intervention, but this categorical movement was not significant.

\section{Research Question Two - Effect on Mathematics Scores}

The results of the statistical analysis found academic recovery students were not more likely to be in the below basic, basic, proficient, or advanced categories on the mathematics component of the MAP test from the 2005-2006 school year to the 20062007 school year. Hypothesis two was not supported. The results were statistically the same from one school year to the next on the Mathematics MAP Test. The movement was minimal. There was one less student in the below basic category and one more student in the basic category after the intervention.

\section{Research Question Three - Comparison of Communication Arts Scores}

The gain score for each student was first calculated. It was found students in academic recovery classes gained a higher average of points on the communication arts section of the MAP Test than a similar group of their peers who were not in academic recovery classes. However, a statistical difference in the gain scores was not found between academic recovery students and the comparison group; hypothesis three was not 
supported. An effect size was then calculated, and the intervention was found to have a small effect on the communication arts test scores (Field, 2005).

The results of another statistical analysis found the academic recovery student's communication arts test scores were significantly different before the intervention than a similar group of students that were not in academic recovery classes. However, after the intervention, the academic recovery student's test scores in communication arts were no longer significantly different than the comparison group. After one year of the intervention, the gap in communication arts scores between the academic recovery students and the comparison group had become smaller.

Additionally, a third statistical analysis found the academic recovery student's communication arts categorical placements were significantly different before the intervention than a similar group of students who were not in academic recovery classes. However, after the intervention, the academic recovery student's categorical placements were no longer significantly different than the comparison group.

Research Question Four - Comparison of Mathematics Scores

The gain score was first calculated for each student. A statistical difference in the gain scores was not found between academic recovery students and the comparison group; hypothesis four was not supported. There was a visible different, but it was not a significant difference. An effect size was then calculated, and the intervention was found to have no effect on the mathematics scores (Field, 2005).

The results of another statistical analysis found academic recovery student's mathematics test scores were significantly different before the intervention, than a similar group of students who were not in academic recovery classes. However, after the 
intervention, the academic recovery student's mathematics test scores were no longer statistically different than the comparison group. After one year of the intervention, the gap in mathematics scores between the academic recovery students and the comparison group had become smaller.

Additionally, a third statistical analysis found the academic recovery student's mathematic categorical placements were significantly different before the intervention than a similar group of students who were not in academic recovery classes. However, after the intervention, the academic recovery student's categorical placements were no longer significantly different than the comparison group. Research Question Five - Student Perceptions

Three themes emerged from the coding of the interview transcripts, the questionnaires, and fieldnotes. They were: connection to school, obstacles at school, and future planning. Academic recovery students were starting to form some connections to school. The academic recovery students preferred hands on learning at school because they thought hands-on learning was fun. The students felt comfortable sharing their work and thoughts in their academic recovery classes, and they had developed some close friendships in these classes. All of the students interviewed felt they had a positive relationship with their academic recovery teacher.

However, the academic recovery students still had some obstacles they were facing at school. Despite the fact the students felt comfortable in academic recovery classes, they were still having a lack of academic success in the classroom. This was making them frustrated and angry. They had many feelings of hate and anger towards 
their non academic recovery teachers and school. Some of the students felt they were being bullied at school outside of their academic recovery classes.

The obstacles the academic recovery students were facing at school were compounded by the academic recovery students' lack of future planning. It was evident through the interviews and questionnaires transcripts, the academic recovery students did not understand what classes they had to take in high school. Many of the students did not even know what they were taking next year. Additionally, it became apparent the students had participated in limited career exploration as they were unsure as to what they were going to do after high school and did not know what classes to take for certain careers. The perceptions of the academic recovery student's experiences in their academic recovery classes were mixed. They had developed some connections to school but still had some obstacles to overcome.

\section{Implications for Practice}

From the findings of the quantitative and qualitative analyses, several implications for practice have emerged. The academic recovery program has had some small success improving student achievement and student perceptions of school. Nevertheless, there is still some work educational leaders need to take to make the effects of the academic recovery program stay with students as they transition from middle school academic recovery classes to high school. First, the findings that are strengths of the program are addressed, with their implications for practice. Then, the findings that are weaknesses of the program are addressed with their implications for practice. 


\section{Strengths of the Program and Implications}

The academic recovery program was not found to have a significant effect on student achievement by the statistical analyses that were conducted, but small successes were evident. Student test scores on the communication arts and mathematics sections of the MAP Test did not decrease; the test scores increased slightly. The academic recovery student's test scores were statistically different than the comparison group before the intervention in both communication arts and mathematics but were not statistically different than the comparison group after the intervention in both communication arts and mathematics. Schweiker-Marra and Pula (2005) conducted a three year study of at-risk middle school students who were placed in a low-track homogenous program, similar to the academic recovery program. They found the number of students testing into the lowest quartile on the Stanford Achievement Test, ninth edition, decreased every year over three years. The increase in student achievement in the academic recovery program could see the same type of results after a few more years. School leaders need to continue to create opportunities for at-risk students to receive support.

School leaders have done a good job identifying the students most at-risk of dropping out of high school. Academic recovery students are identified through low grades in communication arts and mathematics. As Vaughn et al. (2007) stated "students who need additional support in learning these basic skills may be at risk for school failure” (p. 296). Failing grades and test scores are indicators students are at-risk (Suh, Suh, \& Houston, 2007). Educators need to continue to identify students who lack basic skills early and enroll them in academic recovery classes or other similar interventions. 
The academic recovery program is designed to help at-risk middle school students get back on grade level before they enter high school. Few students are being retained or socially promoted in these middle schools. Instead, failing students are placed in academic recovery classes. This is something school officials need to keep doing, as it has been found the traditional methods of retaining students and socially promoting students are unsuccessful in improving student achievement (Ezarik, 2003). When students are retained in middle school, they are $90 \%$ more likely to drop out of school than their peers (Jimerson, Anderson, \& Whippel, 2002). The elimination of retention and social promotion policies are critical steps in improving student achievement.

Successful alternative programs focus on the development of positive relationships and connections to school (Cornelius-White, 2007). The academic recovery classes have facilitated the development of positive relationships giving students some connection to school. Many of the students indicated they had developed friendships in their academic recovery class as well as with their academic recovery teacher. It was evident the academic recovery teachers were using a teaching style that was nurturing; their teaching styles were facilitating the development of a positive relationship with their students (Edward et al., 2007). A positive student/teacher relationship provides a student with a connection to school and the opportunity to have a positive adult role model. The development of positive relationships is one of the most important components of an effective alternative program (Edward et al.), because positive teacher relationships are strong predictors for decreasing drop-out rates (Suh et al., 2007). The facilitation of a strong positive teacher connection in the academic recovery program is something 
educators need to continue to build upon so students can continue to feel this connection to school.

The development of a positive teacher relationships may be attributed to the fact academic recovery students had the same teacher for two or more of their classes. The theory being it allows students more time to develop positive relationships at school (Barr \& Parrett, 1995), master material (Woelfel, 2003), and gives at-risk students more support during the regular school day (Ezarik, 2003). Educational leaders should continue to schedule academic recovery students with the same teacher for several classes so the student/teacher connection can continue to grow. This structure allows small communities of learning to develop and makes it is easier for teachers to keep track of their students (Schweiker-Marra \& Pula, 2005; Wheelock \& Miao, 2005). The time allowed to facilitate these positive connections will pay off in the end as students begin to see a reason in coming to school (McLaughlin \& Vachta, 1992).

\section{Weaknesses of the Program and Implications}

Academic recovery students still need to attain more success at school. Students in academic recovery classes were frustrated by their lack of academic success at school. The students interviewed did not seem to have any real interests at school and seemed to lack the knowledge of why they were in school. None of the students had interests in their core academic classes (communication arts, mathematics, science, and social studies). As a result, many students viewed school negatively, and if this continues, they may not see hope for their future (Edward et al., 2007). The lack of academic success the academic recovery students were having could impede any gain in student achievement because students did not see a point in trying if they were just going to fail. Therefore, 
educators need to quit giving these students the opportunity to fail (Woelfel, 2003).

Teachers need to quit accepting incomplete and failing papers and not allow failure; they should allow students to correct the paper until mastery of the concept.

The students in the academic recovery classes were not involved in extracurricular activities (McLaughlin \& Vachta, 1992). These students had no connections to school outside of their academic recovery classes. The eighth grade students interviewed expressed limited interests in being involved in clubs in high school. The high schools these students were attending are large high schools that have over a thousand students. The academic recovery students had limited connections to school in middle school; they may have no connection in high school. Educators need to do a better job facilitating the exploration of student's interests and inviting them to participate in athletics and clubs in a low risk setting.

If educators are going to help students build a strong connection to school, they need to invite parents into the school. Some of the students expressed lack of interest in school and extracurricular activities may have been facilitated by their parent's lack of knowledge of how important these connections are. These parents need to be invited into the school and taught how to work with their child at home, support their child, and be involved at school (Vaughn et al., 2007). "Students are less likely to engage in poor decision making when they believe significant adults in their lives are united and have their best interests at heart" (Edward et al., 2007, p. 151).

The academic recovery student's lack of future planning should be a concern for the educators. The students interviewed did not seem to have any idea of what classes they were going to take in high school and what career path they would like to take. 
When students were asked what classes they were interested in taking, most of them declared they were interested in taking PE and choir, and they were unsure as to what classes they were taking next year. It was evident most of the students interviewed had not participated in discussions about future careers and the schooling needed for different careers. The student responses were alarming. Many of the students stated they wanted to go to college but had no idea what for, and they had no idea what classes to take to go to college. More career counseling and teacher advisory type systems need to take place in the middle school (Suh et al., 2007), so students can begin to see the congruence between their high school classes and their future careers. These systematic teacher advisory programs should begin in middle school and focus on career and life decision making, problems solving skills, and communication.

The academic recovery program is an intervention at the middle school level. Once students pass eighth grade they are no longer part of the program. They enter high school without any additional support. It is suggested educators form a transition program for academic recovery students from middle school to high school. At-risk students have a difficult time transitioning from one learning experience to the next, and transitions that happen after middle school have been found to be harder on at-risk students. A bridge between the intervention at middle school and high school would give students a better transition and help students feel connected to school (Owings \& Kaplan, 2001; Wheelock \& Miao, 2005). Academic recovery teachers should initiate communication with the academic recovery students' high school teachers (Woelfel, 2003) as part of this transition program. Additionally, these students need help transitioning to the workforce (Barr \& Parrett, 1995). If the academic recovery program grows to a complete transition 
program from middle school to high school to the work force, the students served will have a better chance of succeeding.

\section{Limitations}

This study had several limitations that narrowed the scope of the research. Time was an enormous limitation. This study was only a snapshot of the academic recovery program. Two years of data, before and after the intervention, were used for the quantitative analysis. A longitudinal study would provide for a more detailed study. Time also limited the number of focus group interviews and personal interviews that were conducted. It was the end of the school year, and the researcher had difficulty getting parents to return the consent forms. As a result, the amount of qualitative data was limited. In addition to the limitation of time, the study was conducted by one researcher. School counselors helped in the identification of students and providing data that did not identify students to the researcher (Merriam, 1998; Fink, 2006) and an independent researcher reviewed the findings (Merriam). The researcher collected all data and performed all the analyses.

The study only focused on one alternative middle school program. How the program was implemented was inconsistent at all three school sites. Furthermore, the program was not offered every year at all three sites as the programs viability was determined by the number of full time teachers allocated to the school site by the central office of the school district. If a reduction in staff was required, academic recovery teachers were usually the first ones transferred. This limited the amount of quantitative data the researcher could collect. 
Since the study only focused on one alternative middle school program the sample size used in the study was rather small. There were only fifty-two test scores used in the statistical analysis and only seven students participated in the qualitative study. This limited the amount of data collected and quantitative analyses performed.

Additionally, the MAP Test indicators were changed in 2006 from five stages to four stages. This limited the amount of quantitative data the researcher could collect as test scores before 2006 could not be used because they could not be compared to scores from 2006 and 2007. The limited number of quantitative data made for a small sample. The quantitative analyses consisted of several independent samples $t$-tests. The $t$-test is sensitive to the sample size, and results could be different if the sample size had been larger.

Finally, only one framework guided the study, specifically Patton's (1997) framework of utilization-focused evaluation. The research questions were developed and analyzed from this framework. The utilization of other lenses would have allowed the researcher to explore other aspects of the academic recovery classes. These limitations narrowed the scope of the study and affected what research questions were developed and how they were analyzed.

\section{Recommendations for Further Research}

Several recommendations for further research are presented. These recommendations flow from the limitations that were previously addressed. It is first recommended this study be replicated over a larger time scale. Student achievement data need to be collected for several years and analyzed. A longitudinal study would allow for a more detailed analysis to determine the success of the program, and trends in the data 
could be better identified. The $t$-tests of the student achievement data would be more reliable with a larger sample. More time would allow for more focus group interviews to be conducted with students. This would increase the amount of student input and would allow the researcher to see if the student's perceptions of their experiences in the program change as the program gets more firmly established in the culture of the school.

Further research needs to be conducted to determine if academic recovery students are successful in high school. Following the students to high school would allow insight into if academic recovery students formed connections (Edward et al., 2007) to high school. It would also allow academic recovery leaders insight into if academic recovery students found academic success or dropped out of high school.

More research needs to be done to assess the student/teacher relationship that developed in the program. All students in the program felt they had developed a connection to their teacher. This avenue needs to be explored. It would be ideal if we knew why the students felt they had developed a relationship with their teacher. Additionally, research needs to be done to determine if students sought these types of relationships with their high school teachers.

Furthermore, teacher and parent perceptions of the program need be explored. Student perceptions were the only ones identified in the study. It would be interesting to know if teacher and parent perceptions of the program were the same as the student's perceptions of the program. Teachers developed the goals of the academic recovery programs. If teacher perceptions of the program are different than the student's perceptions, research would need to be conducted to determine why perceptions are different. 
Research needs to be done that includes different types of student achievement data. Student grades and discipline referrals were not accounted for in this study. Further research needs to be done to determine if students grades increased as a result of the academic recovery classes and if the number of discipline referral decreased, since both of these factors are contributing factors to dropping out of high school (McLaughlin \& Vachta, 1992; Suh et al., 2007).

Further research on middle school student's perceptions of what would make middle school more exciting needs to be conducted. Teachers need to know what motivates students to participate in class. Knowing what type of activities interest students should be the catalyst of teacher lesson plans. Middle school student's perceptions of what makes school interesting should be the foundation upon which alternative programs are built.

More research on the interventions facilitated in the academic recovery program needs to be done. Learning the interventions that are most successful for students would help teachers focus their lesson plans and put their energy towards using effective interventions. There is a variety of interventions being used by teachers in the academic recovery program and it is not known if all of them are successful. Determining which intervention is most effective could help the program be more successful.

Lastly, research needs to be done from other perspective than Patton's (1997) theory of utilization-focused evaluation. The "overall effectiveness of" (Patton, p. 67) of the program was not judged as a result of Patton's theory being used as the conceptual underpinning for the study. If this study were conducted from another framework, more information imperative to the program would be found. Conducting the study from the 
teacher-student relationship perspective would provide insight into how a positive teacher-student relationship develops and its importance to the at-risk student. Using McCombs and Whisler's (1997) assessment of learner-centered practices as a lens would allow insight into how effective the program was at focusing on the individual student's learning. Other perspectives would allow for a thorough understanding of the academic recovery program.

Additional research about alternative education needs to be completed. Educators have to continue to address the needs of at-risk students. The number of at-risk youth in this country is increasing, and this is affecting the way schools operate. Alternative interventions have been show to help. The characteristics of these programs need to be disseminated to all school leaders enabling all schools to implement effective alternative programs. 


\section{References}

Anthony, P. (1992). Individuals with disabilities education act: The legacy continues. In P. Anthony \& S. L. Jacobson (Eds.), Helping at-risk students: What are the educational and financial costs? (pp. 1-11). Newbury Park, CA: Corwin Press.

Barr, R. D., \& Parrett, W. H. (1995). Hope at last for at-risk youth. Needham Heights, MA: Allyn \& Bacon.

Bowman, L. J. (2005). Grade retention: Is it a help or hindrance to student academic success? Preventing School Failure, 49(2), 42-46.

Carpentier, S. W. (2007). What if retention were not an option? In R. Dunn \& S. A. Griggs (Eds.), What If? Promising practices for improving schools (pp. 8-12) Lanham, MD: Rowman \& Littlefield Education.

Center on Education Policy. (2004, June). Who's Gaining, Who's Losing \& Why.

Cornelius-White, J. (2007). Learner-centered teacher-student relationships are effective: A meta-analysis. Review of Educational Research, 77(1), 113-143.

Denton, C. A., Fletcher, J. M., Anthony, J. L., \& Francis, D. J. (2006). An evaluation of intensive intervention for students with persistent reading difficulties. Journal of Learning Disabilities, 39(5), 447-466.

Edmonds, R. (1979). Effective schools for the urban poor. Educational Leadership, $3(10), 15-24$.

Edward, O. W., Mumford, V. E., Shillingford, M. A., \& Serra-Roldan, R. (2007). Developmental assets: A prevention framework for students considered at-risk. Children \& Schools, 29(3), 145-153.

Emerson, R. M., Fretz, R. I., \& Shaw, L. L. (1995). Writing Ethnographic Fieldnotes. Chicago: University of Chicago Press.

Ezarik, M. (2003). The road not traveled: Promotion or retention? District Administration, 39(10), 34-38.

Field, A. (2005). Discovering statistics using SPSS: And sex, drugs, and rock ' $n$ ' roll. ( $2^{\text {nd }}$ Edition). Thousand Oaks, CA: Sage Publications.

Fink, A. (2006). How to conduct surveys: A step-by-step guide. Thousand Oaks, CA: Sage Publications.

Flores, M. M., \& Kaylor, M. (2007). The effects of a direct instruction program on the 
fraction performance of middle school students at-risk for failure in mathematics. Journal of Instructional Psychology, 34(2), 84-94.

Franklin, C., Streeter, C. L., Kim, J. S., \& Tripodi, S. J. (2007). The effectiveness of a solution-focused public alternative school for dropout and prevention retrieval. Children \& Schools, 29(3), 133-144.

Glanz, J. (1998). Action research: An educational leader's guide to school improvement. Norwood: MA: Christopher-Gordon Publishers.

Heppner, P. P., \& Heppner, M. J. (2004). A guide to successful theses, dissertations, and publishing research. Pacific Grove, CA: Brooks/Cole.

Jimerson, S. R., Anderson, G. E., \& Whipple, A. D. (2002). Winning the battle and losing the war: Examining the relation between grade retention and dropping out of high school. Psychology in the Schools, 39(4), 441-457.

Johnson, G., Poliner, R., \& Bonaiuto, S. (2005). Learning throughout the day. Educational Leadership, 63(1), 59-63.

Kohn, A. (2003). Almost there, but not quite. Educational Leadership, 60(6), 26-29.

Kourea, L., Cartledge, G., \& Musti-Rao, S. (2007). Improving the reading skills of urban elementary students through total class peer tutoring. Remedial and Special Education, 28(2), 95-107.

Krueger, R. A., \& Casey, M. A. (2000). Focus groups: A practical guide for applied research. $\left(3^{\text {rd }}\right.$ Edition). Thousand Oaks, CA: Sage Publications.

Lapointe, J. M., \& Legault, F. (2004). Solving group discipline problems without coercion: An approach based on attribute retraining. Journal of Classroom Interaction, 39(1), 1-10.

Leckrone, M. J., \& Griffith, B. G. (2006). Retention realities and educational standards. Children \& Schools, 28(1), 53-58.

Mattson, C. E. (2007). Beyond admission: Understanding the pre-college variables and the success of at-risk students. Journal of College Admission, 196, 8-13.

McLaughlin, T. F., \& Vachta, E. F. (1992). The at-risk student: A proposal for action. Journal of Instructional Psychology, 19(1), 66-68.

Menendez, A. L. (2007). Supports and enhancements designed for alternative school programming. Preventing School Failure, 51(2), 19-22.

Merriam, S. B. (1998). Qualitative research and case study applications in education. 
San Francisco: Jossey-Bass.

McCombs, B. L., \& Whisler, J. S. (1997). The learner-centered classroom and school: Strategies for increasing motivation and achievement. San Francisco: JosseyBass.

Missouri Department of Elementary and Secondary Education. (2004, August). Questions and answers about no child left behind. Retrieved January 15, 2008, from http://www.dese.mo.gov/divimprove/fedprog/grantmgmnt/documents/ QA_NCLB_08162004.pdf

Missouri Department of Elementary and Secondary Education. (2005a, November 29). Expanded MAP. Retrieved April 15, 2007, from http://www.dese.mo.gov/divimprove/assess/Expanded_MAP.pdf

Missouri Department of Elementary and Secondary Education. (2005b). Update 2006: The Missouri assessment program. Retrieved April 15, 2007 from http://www.dese.mo.gov/divimprove/assess/2006_map_update.pdf

Missouri Department of Elementary and Secondary Education. (2006a). Missouri assessment program: Guide to interpreting results. Retrieved June 12, 2007 from http://www.dese.mo.gov

Missouri Department of Elementary and Secondary Education. (2006b, November 29). Missouri assessment program (MAP) communication arts data. Retrieved June 12, 2007 from http://dese.mo.gov/planning/profile/MAP09141.htm

Missouri Department of Elementary and Secondary Education. (2006c, November 29). MODESE annual report of school data. Retrieved June, 12, 2007 from http://dese.mo.gov/schooldate/four/039141/demonone.html

Missouri Department of Elementary and Secondary Education. (2006d, August). Missouri assessment program state results, 2006. Retrieved November 18, 2007 from http://dese.mo.gov/divimprove/assess/State_MAP.pdf

Missouri Department of Elementary and Secondary Education. (2006e, Ocotober 26). Consolidated state application accountability workbook. Retrieved November 18, 2007 from http://dese.mo.gov/divimprove/fedprog/AYPTARGETS.html

Missouri Department of Elementary and Secondary Education. (n.d.). Appendix D map score use, meaningfulness, and dependability. Retrieved June 11, 2007 from http://www.dese.mo.gov

Missouri Department of Elementary and Secondary Education. (2007a, August 31). Missouri adequate yearly progress. Retrieved January 6, 2008 from http://dese.mo.gov 
Missouri Department of Elementary and Secondary Education. (2007b, October 31). Understanding your adequate yearly progress (AYP) report 2007-2008. Retrieved November 18, 2007 from http://www.dese.mo.gov/divimprove/sia/dar/understandingyouraypoct07.pdf

Missouri Department of Elementary and Secondary Education. (2007c, November 30). Missouri assessment program (MAP): Springfield R-XII results. Retrieved June 9, 2008 from: http://dese.mo.gov/planning/profile/MAP039141.html

Missouri Department of Elementary and Secondary Education. (2007d, November 30). Missouri assessment program (MAP): Missouri data. Retrieved June 9, 2008, from http://dese.mo.gov/schooldata/MAP000000.html

Missouri Department of Elementary and Secondary Education. (2008, February 15). Missouri department of elementary and secondary education: Springfield $R$-XII (039141) final adequate yearly progress. Retrieved June 10, 2008 from: http://dese.mo.gov/planning/profile/apr/ayp039141.html

Owings, W. A., \& Kaplan, L. S. (2001). Standards, retention, and social promotion. NAASP Bulletin, 85, 57-66.

Patton, M. Q. (1997). Utilization-focused evaluation: The new century text. Thousand Oaks, CA: Sage Publications.

Primont, D. F., \& Domazlicky, B. (2006). Student achievement and efficiency in Missouri schools and the no child left behind act. Economics of Education Review, 25(1), 77-90.

Physics. (2008). Rxc contingency table: How many rows? columns? Retrieved June 9, 2008 from http://www.physics.csbsju.edu/stats/contingency

Reutzel, D. R., Fawson, P. C., \& Smith, J. A. (2006). Words to go!: Evaluating a firstgrade parent involvement program for "making" works at home. Reading and Research Instruction, 45(2), 119-159.

Russo, A. (2005). Retaining retention. Education Next, 5(1), 42-48.

Sagor, S., \& Cox. J. (2004). At-risk students: Reaching them and teaching them. Larchmont, NY: Eye on Education.

Schweiker-Marra, K., \& Pula, J. J. (2005). Effects of homogeneous low-tracked program on academic performance of at-risk students. The Delta Kappa Gamma Bulletin, $71(2), 34-58$.

Seidman, I. (2006). Interviewing as qualitative research: A guide for researchers in education and the social sciences. New York, NY: Teachers College Press. 
Sprague, J. R., \& Walker, H. M. (2005). Safe and healthy schools: practical prevention strategies. In K. W. Merrell (Ed.), The guilford practical intervention in the schools series (pp. 124-147).

Suh, S., Suh, J., \& Houston, I. (2007). Predictors of categorical at-risk high school dropouts. Journal of Counseling \& Development, 85, 196-203.

Thompson, C. L., \& Cunningham, E. K. (2000). Retention and social promotion: Research and implications for policy. (ERIC Digest Number 161). New York, NY: ERIC Clearinghouse on Urban Education. (ERIC Document Reproduction Service No. ED449241).

United States Department of Education. (n.d.). Retrieved January 6, 2008 from www.ed.gov

Vaughn, S., Bos, C. S., \& Schumm, J. S. (2007). Teaching students who are exceptional, diverse, and at risk in the general education classroom. ( $4^{\text {th }}$ edition). Boston, MA: Pearson Education, Inc.

Wheelock, A., \& Miao, J. (2005). The ninth-grade bottleneck. School Administrator, 62(3), 36-40.

Woelfel, K. (2003). Back on track. Principal Leadership, 3(9), 45-48. 


\section{Appendix A}

April 20, 2008

Dear parents and guardians:

I am a doctoral student at the University of Missouri and am conducting research about the academic recovery classes your child is taking. Below is some information about the project.

- I would like to conduct a focus group interview with your child to determine how your child feels about these classes.

- This research will in no way affect your child's grade.

- The results are confidential and will not be shared with your child's teacher. Your child will not be identified.

- Attached is a consent form and letter that further details the study. Please take the time to read these documents and return the consent form.

- Your phone number is requested so I can contact you to determine if before school or after school is most convenient for you.

- A self addressed stamped envelope is provided for you to return the consent form.

- The focus group interviews will take place before or after school.

- Refreshments will be provided for your child.

Your child's insights and thoughts are valuable and would provide a wealth of knowledge about the classes. Thank you for your time. If you have any questions, you may contact me at 887-8690.

Sincerely,

Rachel L. Baker

Researcher

Dr. Cindy MacGregor

Advisor 


\section{Dear parents and guardians:}

I would like permission to have your child participate in a focus group interview about their perceptions and experiences with the academic recovery classes they are taking. This study is part of dissertation project dealing with at-risk programs. I am pursuing my doctorate in Educational Leadership and Policy Analysis through the University of Missouri.

The purpose of this study is to evaluate certain aspects of the academic recovery program classes in your child's school district. This information will be use to determine students' perceptions and experiences associated with the academic recovery classes.

Before you make a final decision about participation, please read the following about how your child's input will be used and how their rights will be protected:

- Participation in the study is completely voluntary. Your child may stop participating at any point without penalty.

- Your child need not answer all the questions.

- The answers will be kept confidential. Results will be presented to others in summary form only, without names or other identifying information.

- Participation will take approximately one hour. During this time your child will answer questions about the academic recovery program classes.

This project follows ethical guidelines in the use of human subjects and adequately safeguards the subject's privacy, welfare, civil liberties, and rights. The project is being supervised by Dr. Cindy MacGregor, Professor of Educational Administration at Missouri State University (417-836-6046; MU IRB phone number: 573-882-9585).

If at this point you are agree for your child to participate and assist with this important research project please, fill out the attached form to give permission for your child to participate in the focus group. You may keep this letter for future reference. You can contact me at 417-523-6800 if you have questions or concerns about your child's participation. Thank you very much for your time and consideration.

Sincerely,

Rachel L. Baker

Enclosure 
I give my permission for my child to participate in a focus group interview. I understand the purpose of the interview is to determine what student perceptions and experience were with the academic recovery program. None of the information will be used against my child and will not affect their grade. All information is confidential and results will be presented in summary form only without names and identifying information. My child has the right not to answer any questions and can withdraw from the interview at any time. This interview will approximately take one hour.

Child name:

Parent or guardian signature:

Date:

Contact Information (phone number): 


\section{Appendix B}

April 20, 2008

Dear student:

I am a doctoral student at the University of Missouri and am conducting research about the academic recovery classes you are in. Below is some information:

- I am conducting an interview with a group of your peers to learn about how you feel about your AR classes.

- This will in no way effect your grade.

- Your teachers will not know what is said, and you will not be identified in my paper.

- Refreshments will be provided.

- Your parents need to fill out the form attached for you to participate.

Your insights and thoughts are valuable to my project. If you have any questions, you may contact me at 887-8690. Thank you for your time.

Sincerely,

Rachel L. Baker

Researcher

Dr. Cindy MacGregor

Advisor 
Dear student:

\section{Consent Form}

I would like to have your parent's permission for you to participate in a focus group interview about the AR classes you are currently taking. This study is part of my dissertation project dealing with at-risk programs. The purpose of this study is to learn about your experiences in your AR classes.

Before you make a decision about participating, please read the following about how your input will be used and how your rights will be protected:

- Participation in the study is completely voluntary. Your may stop participating at any point.

- Your do not have to answer all the questions.

- The answers will be kept confidential. Meaning your teachers will not know what you said, and in my paper you will not be identified.

- The focus group interview will take one hour. During this time you will answer questions about your AR classes.

This project will not harm you in any way and your grade will not be affected. Your rights and privacy will be protected. The project is being supervised by Dr. Cindy MacGregor, Professor of Educational Administration at Missouri State University (417836-6046; MU IRB phone number: 573-882-9585).

You may keep this letter for future reference. You can contact me at 417-523-6800 if you have questions. Thank you very much for your time.

Sincerely,

Rachel L. Baker 


\section{Appendix C}

\section{Focus Group Interview Protocol}

1. What academic recovery classes did you have in middle school?

2. Did you have the same teacher for your classes if you had math and communication arts recovery classes?

3. What did you think of your academic recovery classes while you were enrolled? How much did you like or dislike your classes?

4. What are your interests at school?

5. What do you get excited about at school? What learning excites you?

6. What makes you feel angry at school? Do you hate certain things at school? If so, what things do you hate about school?

7. Describe any friendships in your academic recovery classes you developed? Explain.

8. What was your relationship like with your teacher? Did you feel your teacher cares for you? How?

9. Do you like your teacher? Do you feel your teacher respects you? Explain.

10. Do you feel the classes help you to be more successful in for high school? In what ways?

11. What are some your plans? What classes will you take in high school? What careers are you considering? 


\section{VITA}

Rachel Baker is from Billings, Missouri, were she was born and raised. She attended Missouri State University for her Bachelor's Degree in mathematics education. She was a member of the Honors College. She also received her Master's Degree in Educational Administration from Missouri State. She is married and currently resides in Springfield, Missouri. She taught high school and middle school mathematics for eight years before she took her current position as Assistant Principal at Hillcrest High School in Springfield. 